AperTO - Archivio Istituzionale Open Access dell'Università di Torino

\title{
Extending survival of stage IV non-small cell lung cancer.
}

\section{This is the author's manuscript}

Original Citation:

\section{Availability:}

This version is available http://hdl.handle.net/2318/150387

since 2016-06-10T10:53:25Z

Published version:

DOI:10.1053/j.seminoncol.2013.12.013

Terms of use:

Open Access

Anyone can freely access the full text of works made available as "Open Access". Works made available under a Creative Commons license can be used according to the terms and conditions of said license. Use of all other works requires consent of the right holder (author or publisher) if not exempted from copyright protection by the applicable law. 


\section{(2) \\ UNIVERSITÀ DEGLI STUDI DI TORINO}

Questa è la versione dell'autore dell'opera:

Semin Oncol. 2014 Feb;41(1):69-92. doi: 10.1053/j.seminoncol.2013.12.013. Epub 2013 Dec 21.

Extending survival of stage IV non-small cell lung cancer.

Carnio S, Novello S, Mele T, Levra MG, Scagliotti GV.

La versione definitiva è disponibile alla URL:

http://www.sciencedirect.com/science/article/pii/S0093775413002236 


\section{Extending Survival of Stage IV Non-Small Cell Lung Cancer}

Carnio S, Novello S, Mele T, Levra MG, Scagliotti GV.

Most of patients with newly diagnosed non-small cell lung cancer (NSCLC) present with locally advanced or metastatic disease. In this setting the goal of treatment is to prolong survival and to control disease- and treatment-related symptoms. Currently systemic cytotoxic chemotherapy remains the first-line treatment for most patients with stage IV NSCLC, but preferred treatments are now defined by histology and based on the presence of specific molecular abnormalities. In firstline the combination of platinum plus pemetrexed with or without bevacizumab is a reasonable choice in patients with non-squamous NSCLC. Epidermal growth factor receptor (EGFR) tyrosine kinase inhibitors (TKIs) as first-line therapy are the recommended for patients with EGFRsensitizing mutations. A small-molecule TKI of anaplastic lymphoma kinase (ALK), crizotinib, showed pronounced clinical activity in the treatment of patients with NSCLC positive for EML4ALK and it has rapidly entered into daily clinical practice. Currently no agents are specifically approved for the treatment of squamous cell carcinoma of the lung. Second-line treatments include docetaxel, pemetrexed, or erlotinib as single agents. There is a growing evidence that cytotoxics are better than EGFR-TKIs in EGFR wild-type patients. In the setting of the third line, the only approved agent is erlotinib. In elderly patients with good performance status (PS), doublet chemotherapy including platinum should not be excluded, especially for those patients 70-75 years of age without comorbidities. The better selection of patients, the identification of specific predictive biomarkers, a reasonable sequencing of all active and available treatments, including targeted therapies and cytotoxic, may significantly contribute to extend the natural history of stage IV NSCLC.

Lung cancer remains a relevant health care problem and in the near future will account for almost $30 \%$ of all cancer-related deaths. Non-small cell lung cancer (NSCLC) represents more than $80 \%$ of all lung cancer cases. The majority of patients with lung cancer are diagnosed at baseline with locally advanced or metastatic disease. The increase in life expectancy with the associated cumulative increase in the risk of cancer has led to an increased incidence of this disease in the elderly population. Overall the incidence and death rates for lung cancer are decreasing for both men and women ${ }^{1}$; however, the 5-year survival in stage IV NSCLC remains as low as $1 \% .{ }^{2}$ According to the current World Health Organization (WHO) classification for lung tumors, NSCLC includes many histological subtypes, but for therapeutic purposes it can be broadly categorized as squamous and non-squamous. This non-canonical categorization is related to the lack of efficacy of some cytotoxic agents (eg, pemetrexed) or to an excess of toxicity for some targeted agents (eg, bevacizumab and other multiple vascular endothelial growth factor [EGFR] inhibitors) in squamous histology. As consequence over the last few years the histological definition became progressively more important in tuning the therapeutic choices and now is definitively recognized the role of immunohistochemistry in minimizing the amount of NSCLC not otherwise specified (NOS).

Here, we summarize the available data about the best treatment strategy in front line for stage IV NSCLC on the basis of the predictive role of histology and new molecular findings and reviews new data about the treatment customization in elderly patients, as well as treatment choices in second line and beyond.

\section{Treatment Choices In First Line}

\section{The Role of Cytotoxic Chemotherapy}

First-line chemotherapy improves survival in patients with advanced NSCLC and good performance status (PS). It generally includes two chemotherapy agents with different mechanisms of action and safety profiles. $\underline{\underline{3}}$ and $\underline{4}$ Several studies $\underline{\underline{5}}, \underline{6}, \underline{7}$ and $\underline{8}$ and multiple meta-analyses $\underline{\underline{9}}, \underline{10}$ and $\underline{11}$ 
established the superior efficacy of doublet regimens over single agents and the superior activity of cisplatin over carboplatin in terms of objective response rate $(\mathrm{ORR})^{\frac{12}{2}}$ despite a less favorable toxicity profile. Improvements in survival were observed in subgroups of cisplatin-treated patients who had been treated with third-generation platinum-based regimens (hazard ratio [HR] for mortality with carboplatin relative to cisplatin $=1.11 ; 95 \%$ confidence interval $[\mathrm{CI}], 1.01-1.21)$ and in patients with non-squamous histology $(\mathrm{HR}=1.12 ; 95 \% \mathrm{CI}, 1.01-1.23)$.

A decade ago several large randomized clinical trials compared different platinum-based doublets (including third-generation agents such taxanes, gemcitabine, or vinorelbine) without showing significant differences in ORR, progression-free survival (PFS), and overall survival (OS). $\underline{13}, \underline{14}$ and $\underline{15}$ A meta-analysis investigated the role of adding a third agent to platinum-based doublets and showed that triplets are associated with an increase in ORR, which does not translate into a better PFS or OS rate. $\frac{16}{}$ Traditionally, the histologic subtype did not matter for the choice of chemotherapy but the therapeutic landscape changed following the results of a large phase III randomized non-inferiority study conducted in 1,725 patients with stage IIIB or IV NSCLC that compared cisplatin plus pemetrexed (CP) to cisplatin plus gemcitabine (CG). A preplanned analysis for histology showed that patients with non-squamous histology benefited more from $\mathrm{CP}$ in terms of OS (HR 0.81; $P=.005$ ), while PFS did not differ between the two groups. On the contrary, patients with squamous cell histology showed a marginally significant superiority in OS when treated with CG $(10.8 v 9.4$ months, respectively; HR $1.23 ; P=.05)$ and PFS was also significantly longer (5.5 $v 4.4$ months, respectively; HR 1.36; $P<.05)$. CP resulted in a statistically significant inferior incidence of grade 3-4 neutropenia, anemia, thrombocytopenia, febrile neutropenia, and alopecia $(P \leq .001)$, whereas drug-related grade $3-4$ nausea was higher $(P=.004)$. 17 and $\underline{18}$ Hypothesis-generating findings support the superior activity of pemetrexed in non-squamous NSCLC on the basis of the differential expression of thymidylate synthase (TS), one of the target enzymes of pemetrexed, among the different histotypes of lung cancer being TS lower in adenocarcinoma than in squamous cell carcinoma. $\frac{19}{}$ Supportive data indicate extremely high levels of TS in small cell lung cancer where pemetrexed did not show activity. $\underline{20}$

Nab-paclitaxel is a biologically interactive albumin-bound paclitaxel and in a phase II trial showed improvement of clinical outcomes with weekly rather than every-3-week administration..$^{21}$ Subsequently, a phase III randomized trial evaluated nab-paclitaxel plus carboplatin (nab-PC) versus standard-paclitaxel plus carboplatin (sb-PC). Nab-PC demonstrated a significantly higher ORR than sb-PC (33\% v 25\%; $P=.005)$. Although ORR by histology was not a prespecified endpoint of the study, nab-PC was significantly more active than sb-PC in patients with squamous histology. nab-PC was as effective as sb-PC in patients with non-squamous histology. In general, nab-PC was better tolerated, with lower rates of grade 3 and 4 neuropathy, neutropenia, arthralgia, and myalgia. $\underline{22}$

\section{Molecular Agents Inhibiting Tumor Angiogenesis}

Angiogenesis involves multiple cellular events and many interactions among a variety of cell types. While the primary stimulus for angiogenesis in the tumor microenvironment is the hypoxia-driven activation of hypoxia-inducible factor- $1 \alpha$ (HIF-1 $\alpha)$, and the subsequent activation of vascular endothelial growth factor (VEGF), numerous other growth factors and protein products of oncogenes and tumor-suppressor genes are also involved. $\underline{23}$ Tumor-associated vasculature fails to mature completely, typically due to the development of hypoxic regions in the tumor that stimulate a perpetual cycle of VEGF production, angiogenesis, and further tumor growth. ${ }^{24}$

\section{Vascular Endothelial Growth Factor and Receptor Inhibitors}

Bevacizumab, an anti-VEGF humanized monoclonal antibody which inhibits the interaction between the ligand and VEGF receptors (VEGFRs), has been the first targeted agent approved for the treatment of first-line of metastatic non-squamous NSCLC. The activity of bevacizumab in 
combination with chemotherapy has been evaluated in two large phase III clinical trials (Eastern Cooperative Oncology Group [ECOG] trial E4599 and AVAstin in Lung Cancer [AVAiL]). ECOG 4599 randomly assigned 855 PS $0-1$ patients with advanced non-squamous NSCLC to receive carboplatin-paclitaxel with or without bevacizumab. The primary endpoint of the study was OS. Patients with squamous histology, those with a history of hemoptysis, brain metastases, bleeding or thrombotic disorders, or the need for anticoagulation were also excluded from the study. The exclusion of patients with squamous histology was mandated from life-threatening or fatal episodes of hemoptysis observed in a phase randomized II trial of bevacizumab plus chemotherapy. ${ }^{25}$ All the efficacy endpoints were significantly improved with bevacizumab (median OS 12.3 months $v 10.3$ months [HR 0.80; $P=.003$ ] and median PFS $6.2 v 4.5$ months, respectively [HR $0.66 ; P<.001]) . \stackrel{26}{ }$ Subgroup analyses suggested that the magnitude of benefit was greater in patients with

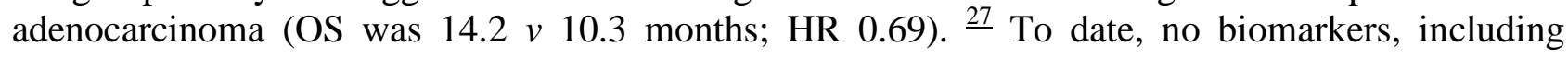
hypertension, have been identified to reliably predict patients with improved survival from the addition of bevacizumab. $\underline{28}$

Bevacizumab was also evaluated in combination with cisplatin plus gemcitabine in the another (AVAiL) study in 1,050 patients testing two different dose levels, 7.5 and $15 \mathrm{mg} / \mathrm{kg}$, and having as the primary endpoint PFS. The addition of bevacizumab significantly increased PFS from 6.1 to 6.5 or 6.7 months (in the high- and low-dose groups, respectively; HRs for PFS were $0.75 ; P=.0003$ and $.85 ; P=.04)$. No difference in OS was observed. ORR was also significantly higher in both bevacizumab arms $(37.8 \%, P<.0001$, and $30.6 \%, P=.0002$, respectively) versus $21.6 \%$ for the chemotherapy arm. $\stackrel{29}{2}$ Treatment with bevacizumab was generally well tolerated, even if more severe bleeding episodes were observed in the bevacizumab arm $(4.4 \% v 0.7 \%$, respectively; $P<.001)$.

The reasons why these two studies ended up in partially different results is not known, but it could be partially related to differences in the patient cohorts, the inferior activity of paclitaxel and carboplatin versus cisplatin and gemcitabine, and the in vitro evidence of synergy between taxanes and bevacizumab. $\underline{30}$

Despite the modest OS benefit and the conflicting data bevacizumab added chemotherapy was recommended and progressively implemented in several therapeutic guidelines in patients with stage IV non-squamous NSCLC with good PS and without brain metastases and haemoptysis. $. \underline{31}, \underline{32}$, $\underline{33}, \underline{34}$ and $\underline{35}$

Recently a systematic review and meta-analysis of four randomised phase II/III trials confirmed that bevacizumab significantly prolonged OS (HR 0.90; $P=.03$ ), and PFS $(0.72 ; P<.001)$. Bevacizumab also showed a significantly greater effect on OS in patients with adenocarcinoma versus other histologies $(P=.02)$, and in patients with body weight loss $\leq 5 \%$ versus $>5 \%(P=.03)$. $\underline{36}$

Patients with CNS metastases were initially excluded because of the risk of cerebral hemorrhage. Nevertheless, the available data suggest an equal risk of intracranial bleeding in patients with CNS metastases treated with or without bevacizumab. In a phase II study (PASSPORT) the safety of bevacizumab in patients with advanced NSCLC and PS 0-1 previously treated for brain metastases (including whole-brain radiation therapy, radiosurgery, and/or neurosurgery) was prospectively evaluated. Patients received bevacizumab in combination with platinum-based doublet chemotherapy or erlotinib as front-line treatment, while second-line bevacizumab was added to the investigators' treatment choice (erlotinib, pemetrexed, docetaxel). Bevacizumab was administered at the dose of $15 \mathrm{mg} / \mathrm{kg}$ every 21 days until disease progression or unacceptable toxicity for a maximum of 1 year. The primary objective of the study was the incidence of symptomatic grade $\geq 2$ CNS hemorrhage. One hundred fifteen patients were enrolled and full-dose anticoagulation was allowed. Brain imaging was performed at screening and then every 6-8 weeks. No episode (grade 15) of CNS hemorrhage was reported. Other toxicities were consistent with those previously 
reported. $\frac{37}{}$ Additional safety data came from ARIES (Avastin Registry: Investigation of Effectiveness and Safety), a prospective observational cohort study in colorectal cancer and NSCLC that included patients underrepresented in randomized clinical trials, ie, elderly patients, with poor PS, or with CNS metastasis. Among 150 patients with NSCLC and CNS metastases no episodes of CNS bleeding were documented. $\frac{38}{}$ A retrospective exploratory analysis of 13 randomized trials evaluated the safety of bevacizumab in patients with pre-existing brain metastases or with brain metastases detected when patients were already receiving bevacizumab. $\frac{39}{}$ Three of these studies included patients with NSCLC for a total of 8,443 patients of whom 4,760 received bevacizumab. Occult brain metastases were identified in 187 of 8,443 patients (91 in bevacizumab arms and 96 in non-bevacizumab arms). Three patients $(3.3 \%)$ in the bevacizumab group developed a grade 4 cerebral hemorrhage, compared with one of 96 control patients $(1 \%)$ who experienced a grade 5 cerebral hemorrhage. Mortality rate was not different between the two groups. $\underline{25}, \underline{26}$ and $\underline{29}$

SaiL (Safety of Avastin in Lung) is another large phase IV study undertaken to assess the safety and efficacy of first-line bevacizumab combined with several standard chemotherapy regimens in patients with advanced or recurrent non-squamous $\mathrm{NSCLC}^{40}$ and another open-label trial (ATHENA $)^{41}$ evaluated the safety of bevacizumab in patients with CNS metastases and breast cancer. One hundred eighty-one of the 2,166 patients in SAiL (8.4\%) and 140 of the 2,216 patients in ATHENA $(6.3 \%)$ developed brain metastases. Six of these patients were treated with bevacizumab after diagnosis of CNS metastases, none of whom developed cerebral hemorrhage. Three patients in the SAiL study $(0.9 \%$ of the patients in the two studies who developed brain metastases) had cerebral hemorrhage, only one grade 3. In the ATLAS study (The Avastin Tarceva Lung Adenocarcinoma Study) $)^{42}$ patients with advanced NSCLC who had already treated with an induction treatment including bevacizumab, in the absence of disease progression, were randomly assigned in the maintenance portion of the study either to continue bevacizumab alone or in combination with erlotinib. Patients with treated brain metastases were allowed; only one patient developed a grade 2 cerebral hemorrhage after disease progression. A further review of 57 trials that included 10,598 patients evaluated the safety and efficacy of different anti-VEGF therapies (bevacizumab in 22 trials, sorafenib in 12, sunitinib in 5, and a variety of other agents in 18). Brain

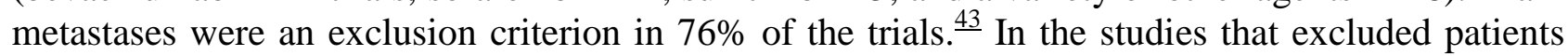
with brain metastases (1,755 patients) only two episodes of CNS bleeding were reported $(<1 \%)$. In the four studies that included patients with brain metastases (2688 patients) there were no episodes of intracranial hemorrhage. In conclusion, several retrospective studies and at least one prospective study confirmed that bevacizumab may be safely used in patients with brain metastases.

In AVAiL, patients remained on study if anticoagulation for venous thrombosis was started while the patient was already treated. Nine percent of patients received therapeutic anticoagulation with either warfarin or low-molecular-weight heparin, and no pulmonary hemorrhages were observed. A retrospective analysis was performed to assess the effect of anticoagulation in AVAiL and in other

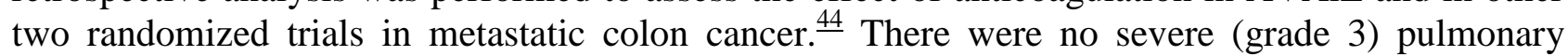
hemorrhages in any of the patients receiving anticoagulation and treated with bevacizumab. In SAiL, $15 \%$ of patients received concomitant anticoagulation at some point during treatment, and the overall risk of grade $\geq 3$ bleeding was low $(4 \%)$, as well as the risk of grade $\geq 3$ pulmonary hemorrhage (1\%). Among 1065 patients who completed one or more cycles of bevacizumab, a total of 227 bleeding events occurred in 181 patients (17\%) versus 19 bleeding events in 15 of 87 patients $(17.2 \%)$ receiving anticoagulants. $\underline{45}$ Therefore, anticoagulation does not increase the risk of bleeding during treatment with bevacizumab.

Data about the safety of bevacizumab in patients with a poor PS are limited. A preliminary report from ARIES included 182 patients with a PS of $\geq 2$. These patients had a worse clinical outcome in terms of PFS and OS compared to the general population.

Several retrospective analyses were performed to identify the potential risk factors associated with pulmonary hemorrhage $(\mathrm{PH})$ in patients treated with bevacizumab, $\underline{46}$ including central tumor 
location, cavitation, and vessel invasion especially in patients on anticoagulant therapy. None of the clinical or radiological features proved to be reliable predictive factors for severe PH. Major blood vessel and bronchial vessel infiltration, encasement, and abutting may predict $\mathrm{PH}$. However, standardized radiological criteria for defining vessel infiltration have not been established. Hypothetically, dilation of the bronchial artery could be a risk factor for $\mathrm{PH}$, but no conclusive data exist to support this hypothesis. A high-resolution computed tomography scan should be used to assess PH occurring in non-squamous NSCLC patients treated with bevacizumab. $\stackrel{47}{ }$

Recently, two small studies investigating bevacizumab in combination with chemo-radiotherapy reported an alarmingly high rate of tracheal-esophageal fistula formation. ${ }^{48}$ However, another study has reported acceptable toxicity ${ }^{49}$ and additional studies are ongoing.

Because of the higher efficacy of pemetrexed and bevacizumab in non-squamous NSCLC these two agents have been recently tested with carboplatin in a series of clinical studies. In a multicenter phase II study bevacizumab and pemetrexed maintenance after an initial therapy with pemetrexed

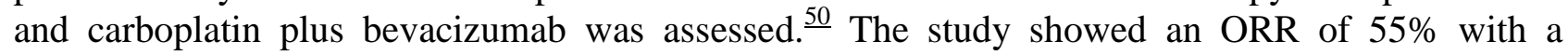
favorable toxicity profile. Median PFS and OS were 7.8 and 14.1 months, respectively. These promising results led to the subsequent phase III (PointBreak) randomized study of pemetrexed/carboplatin plus bevacizumab as induction followed by pemetrexed and bevacizumab maintenance compared with paclitaxel/carboplatin plus bevacizumab as induction followed by bevacizumab maintenance in chemotherapy-naive patients with advanced non-squamous NSCLC. $\underline{51}$ The primary endpoint of superior OS for the pemetrexed arm was not met (12.6 $v 13.4$ months, HR $1.00, P=.949)$; however, the study showed a modest improvement in PFS for the pemetrexed arm (6.0 $v 5.6$ months, HR $0.83, P=.012)$ and a good safety profile. $\underline{52}$

A post hoc analysis of patients $\geq 70$ years of age in ECOG 4599 previously detected increased adverse events and numerically decreased survival benefit associated with bevacizumab compared to patients $<70$ years of age. A pooled analysis of ECOG 4599 and PointBreak data based on age was recently presented..$^{53}$ The statistically significant benefit associated with the addition of bevacizumab to chemotherapy was consistently reported across all age groups $<75$ years. Patients $\geq 75$ years receiving bevacizumab had a higher incidence of grade $\geq 3$ adverse events relative to chemotherapy alone with no statistically significant survival benefit, although increased grade $\geq 3$ adverse events were observed in all age groups.

Another phase III study (PRONOUNCE) evaluated pemetrexed/carboplatin followed by maintenance therapy with pemetrexed compared with bevacizumab plus paclitaxel/carboplatin followed by maintenance therapy with bevacizumab. The primary endpoint was PFS without grade 4 toxicity (G4PFS) according to a superiority study design. $\underline{54}$ Top line data indicate that pemetrexed/carboplatin was not superior to carboplatin/paclitaxel/bevacizumab in terms of G4PFS and no difference in PFS or OS between the two regimens were observed.

Ramucirumab is an investigational monoclonal antibody that binds to VEGFR-2 and blocks ligand

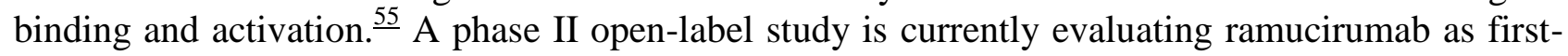
line therapy in combination with carboplatin/paclitaxel, with preliminary results from the first 15 patients reporting an overall RR of $67 \% . \frac{56}{}$ Another phase II trial is recruiting patients with previously untreated NSCLC to examine ramucirumab in combination with four different chemotherapeutic regimens as first-line therapy, and a phase III trial is recruiting patients with NSCLC to test ramucirumab in combination with docetaxel as second-line therapy after failure of platinum-based therapy.

\section{Multi-targeted Anti-angiogenetic Agents}

Efforts to identify drugs that inhibit key pathways involved in the pathogenesis of cancer have led to the development of multi-targeted agents. Small-molecule TKIs that inhibit receptors such as 
VEGFR, platelet-derived growth factor receptor (PDGFR), Raf, and KIT simultaneously may offer advantages over agents with single targets, and therefore a higher likelihood of single-agent activity. In addition, as multi-targeted TKIs are often available orally they may be more convenient for patients. Conversely, a potential disadvantage is the potential for toxicity resulting from offtarget kinase inhibition, and additive toxicity, which may be particularly relevant when the agents are combined with chemotherapy.

Sorafenib is a Raf and VEGFR inhibitor (VEGFR-2 and VEGFR-3) with activity against PDGFR and KIT. In xenograft models, sorafenib plus vinorelbine, cisplatin or gefitinib resulted in tumor growth delay at least comparable to that observed with each agent alone. The phase III ESCAPE trial tested carboplatin plus paclitaxel with or without sorafenib as first-line treatment in advanced NSCLC. The primary endpoint of OS was not met and the study was terminated early due to the detrimental effect of sorafenib in patients with squamous cell carcinoma and the lack of effect in non-squamous cell carcinoma. ${ }^{57}$ Similarly, another phase III study (NExUS) evaluated sorafenib with gemcitabine plus cisplatin did not meet the primary endpoint of OS. Patients with squamous histology were excluded from this study based on the results of ESCAPE. $\underline{58}$

Motesanib, a VEGFR-1, -2, and -3, PDGFR, KIT, and RET inhibitor was investigated in multiple tumor types including NSCLC. In a phase II trial $(n=186)$ motesanib was combined with carboplatin and paclitaxel and showed comparable efficacy to bevacizumab plus carboplatin and paclitaxel. $\underline{\text { I9 }}$ In a phase III trial (MONET1), 1,090 patients with advanced non-squamous NSCLC received carboplatin and paclitaxel with or without motesanib; preliminary results reported that neither PFS (5.6 $v 5.4$ months; HR 0.785; $P=.006)$ nor OS (13.0 v. 11.0 months; HR 0.897; $P=$ $.137)$ were significantly improved and grade $\geq 3$ adverse events were more frequent with motesanib. $\underline{60}$

\section{Vascular-Disrupting Agents}

Vascular-disrupting agents (VDA) are compounds that directly target blood vessels and create central tumor necrosis. VDAs have demonstrated signs of clinical activity in different tumor

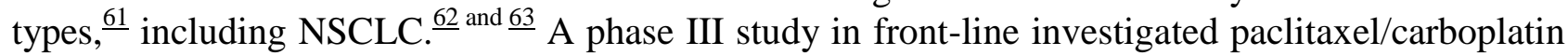
with or without ASA404 was terminated early because an interim analyses showed no increase in OS. $\stackrel{64}{ }$

As a class of agents, the clinical development is hampered by cardiovascular and neurological toxicities as single agents, and by hematologic toxicity in combination with chemotherapy and currently there is no predictive marker to identify patients with a high probability of response.

\section{Epidermal Growth Factor Receptor Pathway}

\section{Tyrosine Kinase Inhibitors}

EGFR is a transmembrane protein with cytoplasmic kinase activity that transduces growth factor signaling from the extracellular milieu to the cell. More than $60 \%$ of NSCLCs express EGFR and this receptor is now a relevant therapeutic target for the treatment of these tumors. TKIs of EGFR are especially effective in patients whose tumors harbor activating mutations in the EGFR gene and several trials have concluded that initial therapy with a EGFR-TKI instead of chemotherapy is the best treatment choice in patients with tumors harboring a sensitizing mutation (Table 1). Therefore, mutation testing is mandatory to identify these patients, given that selection based only on clinicalpathologic characteristics is inadequate. They include never-smoking status, female gender, the histologic diagnosis of adenocarcinoma, and the Asiatic ethnicity.

Table 1. 
Phase III Randomized Studies Comparing TKIs to Platinum-Based Chemotherapy as FirstLine Treatment in "Selected" NSCLC

\begin{tabular}{|c|c|c|c|c|c|c|}
\hline \multirow{2}{*}{ Study } & \multirow{2}{*}{ Treatment } & \multicolumn{2}{|c|}{\begin{tabular}{|c||} 
EGFR Mutational \\
Status
\end{tabular}} & \multirow{2}{*}{$\begin{array}{c}\text { ORR } \\
(\%)\end{array}$} & \multirow[b]{2}{*}{$\|$ PFS (mo) } & \multirow[b]{2}{*}{ OS (mo) } \\
\hline & & \begin{tabular}{||c|} 
Test \\
Performed \\
$(\%)$ \\
\end{tabular} & \begin{tabular}{|c|} 
Test \\
Positive \\
$(\%)$ \\
\end{tabular} & & & \\
\hline \multirow[t]{4}{*}{ IPASS $^{74}$} & $\begin{array}{l}\text { Gefitinib } v \\
\text { Carbo/Placli }\end{array}$ & $35.9 \%$ & $59.7 \%$ & $\begin{array}{l}43.0 v \\
32.3\end{array}$ & $5.7 v 5.8$ & $18.6 v 17.3$ \\
\hline & & & & $\begin{array}{c}P= \\
.0001 \\
\end{array}$ & HR: 0.74 & HR: 0.91 \\
\hline & & & & & \begin{tabular}{|c|}
$95 \%$ CI: \\
$0.65-0.85$ \\
\end{tabular} & \begin{tabular}{|r|}
$95 \%$ CI: \\
$0.76-1.10$ \\
\end{tabular} \\
\hline & & & & & \begin{tabular}{|l|}
$P<.0001$ \\
\end{tabular} & $P=.11$ \\
\hline \multirow[t]{4}{*}{\begin{tabular}{|l} 
First- \\
SIGNAL $\underline{\text { 76 }}$ \\
\end{tabular}} & Gefitinib $v$ Cis/Gem & $31.6 \%$ & $43.7 \%$ & $\begin{array}{l}53.5 v \\
45.3\end{array}$ & $6.1 v 6.6$ & $21.3 v 23.3$ \\
\hline & & & & $P=.153$ & HR: 0.81 & HR: 1.00 \\
\hline & & & & & \begin{tabular}{|r|}
$95 \%$ CI: \\
$0.64-1.03$
\end{tabular} & \begin{tabular}{|c|}
$95 \%$ CI: \\
$0.75-1.34$
\end{tabular} \\
\hline & & & & & $P=.044$ & $P=.428$ \\
\hline \multirow[t]{4}{*}{ WJTOG $^{78}$} & Gefitinib $v$ Cis/Doce & $100 \%$ & $100 \%$ & $\begin{array}{l}62.1 v \\
32.2 \\
\end{array}$ & $9.2 v 6.3$ & $30.9 v \mathrm{nr}$ \\
\hline & & & & $P<.0001$ & HR: 0.49 & HR: 1.64 \\
\hline & & & & & \begin{tabular}{|r|}
$95 \%$ CI: \\
$0.34-0.71$ \\
\end{tabular} & \begin{tabular}{|c|}
$95 \%$ CI: \\
$0.75-3.58$ \\
\end{tabular} \\
\hline & & & & & $P<00001$ & $P=.211$ \\
\hline \multirow[t]{4}{*}{ NEJO02 ${ }^{\frac{79}{}}$} & \begin{tabular}{|l} 
Gefitinib $v$ \\
Carbo/Placli
\end{tabular} & $100 \%$ & $100 \%$ & $\begin{array}{l}73.7 v \\
30.7\end{array}$ & $\mid 10.8 v 5.4$ & $30.5 v 23.6$ \\
\hline & & & & $P<.001$ & HR: 0.30 & $P=.31$ \\
\hline & & & & & \begin{tabular}{|c|}
$95 \%$ CI: \\
$0.22-0.41$ \\
\end{tabular} & \\
\hline & & & & & $P<.001$ & \\
\hline \multirow[t]{4}{*}{ OPTIMAL $^{80}$} & $\begin{array}{l}\text { Erlotinib } v \\
\text { Carbo/Gem }\end{array}$ & $100 \%$ & $100 \%$ & $\begin{array}{l}83.0 v \\
36.0\end{array}$ & $\mid 13.1 \vee 4.6$ & ns \\
\hline & & & & $P<.0001$ & \begin{tabular}{|l|} 
HR: 0.16 \\
\end{tabular} & \\
\hline & & & & & \begin{tabular}{|c|}
$95 \%$ CI: \\
$0.10-0.26$ \\
\end{tabular} & \\
\hline & & & & & $P<.0001$ & \\
\hline \multirow[t]{4}{*}{ EURTAC ${ }^{81}$} & Erlotinib $v$ platinum & $100 \%$ & $100 \%$ & $\begin{array}{l}63.6 v \\
17.8\end{array}$ & $9.7 v 5.2$ & $19.3 v 19.5$ \\
\hline & based chemotherapy & & & $P<.0001$ & HR: 0.37 & HR: 1.04 \\
\hline & & & & & \begin{tabular}{|c|}
$95 \%$ CI: \\
$0.25-0.54$ \\
\end{tabular} & \begin{tabular}{|c|} 
95\% CI: \\
$065-1.68$ \\
\end{tabular} \\
\hline & & & & & $P<.0001$ & $P=.87$ \\
\hline
\end{tabular}




\begin{tabular}{|c|c|c|c|c|c|c|}
\hline \multirow{2}{*}{ Study } & \multirow{2}{*}{ Treatment } & \multicolumn{2}{|c|}{$\begin{array}{c}\text { EGFR Mutational } \\
\text { Status }\end{array}$} & \multirow{2}{*}{$\begin{array}{c}\text { ORR } \\
(\%)\end{array}$} & \multirow[b]{2}{*}{ PFS (mo) } & \multirow[b]{2}{*}{ OS (mo) } \\
\hline & & \begin{tabular}{|c|} 
Test \\
Performed \\
$(\%)$ \\
\end{tabular} & \begin{tabular}{|c|} 
Test \\
Positive \\
$(\%)$ \\
\end{tabular} & & & \\
\hline \multirow[t]{4}{*}{$\begin{array}{l}\text { LUX-Lung } \\
3^{\underline{88}}\end{array}$} & Afatinib $v$ Cisplatin/ & $100 \%$ & $100 \%$ & $\begin{array}{l}56.0 v \\
23.0\end{array}$ & $11.1 \vee 6.9$ & NR \\
\hline & Pemetrexed & & & $P<.0001$ & HR: 0.58 & \\
\hline & & & & & \begin{tabular}{|c|}
$95 \%$ CI: \\
$0.43-0.78$ \\
\end{tabular} & \\
\hline & & & & & $\begin{array}{c}P= \\
.0004\end{array}$ & \\
\hline \multirow[t]{3}{*}{$\begin{array}{l}\text { LUX-Lung } \\
6^{\underline{89}}\end{array}$} & $\begin{array}{l}\text { Afatinib } v \\
\text { Cisplatin/Gemcitabine }\end{array}$ & $\mid 100 \%$ & $100 \%$ & $\mid 66.9 v 23$ & $\mid \begin{array}{l}11.0 \vee 5.6 \\
\text { HR:0.28 }\end{array}$ & $\begin{array}{l}\text { OS based } \\
\text { on } 43 \% \text { of } \\
\text { events } \\
\text { shows }\end{array}$ \\
\hline & & & & $P<.0001$ & $P<.0001$ & $\mathrm{HR}=.95$ \\
\hline & & & & & & $P=.7593$ \\
\hline
\end{tabular}

Abbreviations: Cis, cisplatin; Gem, gemcitabine; Carbo, carboplatin; Pacli, paclitaxel; Doce, docetaxel; ns, not specified; nr, not reached

ORR, objective response rate; PFS, median progression-free survival; OS, median overall survival; HR, hazard ratio; CI, confidence interval; NR, not reported.

Platinum-based chemotherapy options: Cis/Gem or Cis/Doce or Carbo/Doce or Carbo/Gem.

Gefitinib and erlotinib are first-generation TKIs that selectively target EGFR. Looking back to early single -agent studies with gefitinib (IDEAL-1 and IDEAL-2), initially performed in unselected and previously treated patients, some anti-tumor activity was shown with response rates ranging from $12 \%-18 \%$, a disease control rate of $42 \%-54 \%$, with most of the responses achieved within $4-5$ weeks, and when patients responded a considerable tumour shrinkage was observed. Activity was superior in adenocarcinoma, females, and never-smokers. $\underline{65}$ and $\underline{66}$

These results and the preclinical evidence in preclinical models of a synergism with chemotherapy led to two large randomized phase III trials that explored the efficacy of gefitinib in combination with platinum-based chemotherapy. Both studies did not demonstrate any statistically significant difference in OS between arms and similar results were reported with erlotinib. $\underline{67}, \underline{68}, \underline{69}, \underline{70}, \underline{71}$ and $\underline{72} \mathrm{~A}$ confirmation of the limited efficacy of EGFR-TKIs in unselected patient population came from the Iressa Survival Evaluation in Lung Cancer (ISEL) trial, a large multicenter phase III trial that compared single-agent gefitinib versus placebo in 1,692 patients with advanced NSCLC after failure of one or two prior chemotherapies and OS was comparable in the two arms. $\underline{73}$

The Iressa Pan-Asia Study (IPASS) trial was performed in a clinically selected population of Asian adenocarcinoma patients, who were never-smokers or with limited smoking history $(\leq 10$ pack-years and $\geq 15$ years since quitting) and involved nine countries across Asia. One thousand two hundred seventeen patients were randomized to first-line gefitinib or carboplatin-paclitaxel and the primary end point of the study was the non-inferiority of gefitinib. ${ }^{74}$ The results showed the superiority of PFS for gefitinib compared with chemotherapy in the entire study population (HR 0.74). EGFR mutation analysis was performed on 437 patients (35.9\%) and, of these, $60 \%$ were positive for one 
of the panel of 29 mutations detected by the EGFR kit (DxS, Rotor-Gene Q 5plex, QIAGEN, GER). Among the 261 known EGFR mutants, the benefit of first-line gefitinib was even stronger with a further improvement in PFS (HR 0.48), an increased RR (71\% on gefitinib $v 47 \%$ on chemotherapy). Final OS data based on $78 \%$ of the events, showed no differences between gefitinib and chemotherapy in the entire population (18.6 $v 17.3$ months, respectively; HR $0.91, P=.11)$ and in the mutation-positive subgroup (HR 1.00). In addition, patients with EGFR-mutated tumors in the gefitinib group had a clinically relevant improvement in quality of life and a lower incidence of grade 3-4 adverse events compared to chemotherapy.

A second study randomized 313 Korean never-smokers with adenocarcinoma to gefitinib or cisplatin-gemcitabine. Overall, there was no significant difference between the arms in terms of PFS or OS. Similarly to IPASS, gefitinib improved PFS versus chemotherapy in mutation-positive patients (without reaching the statistical significance) but worsened PFS in mutation-negative patients. OS did not differ between the groups regardless of EGFR status. ${ }^{76}$

The results of the IPASS trial were really practice-changing because of both the impressive results in the EGFR mutation-positive group and the fact that the EGFR mutation-negative patients treated with gefitinib did fairly poor (PFS HR 2.85). These results showed that it is harmful to treat patients who do not harbor EGFR mutations with first-line EGFR-TKIs, even if they are never-smokers with adenocarcinoma, and that patients are best screened by genotype testing to determine the most appropriate first-line treatment.

The efficacy of EGFR-TKIs in EGFR mutation-positive patients has been further confirmed in three prospective randomised studies performed in Asiatic patients, $\underline{77}$ and $\underline{78}$ as well as in one study in Caucasian patients. ${ }^{79}$ In all of these studies EGFR-TKIs were associated with a more favorable toxicity profile and improved quality of life. OS ranged from 21.6-30.5 months and was highly influenced by high cross-over rates, with up to $95 \%$ of patients receiving EGFR-TKIs after failure of chemotherapy, suggesting that these agents are effective independently from the line of therapy.

The American Society of Clinical Oncology (ASCO) Clinical Practice Guidelines in 2009 recommended gefitinib as first-line treatment for patients with activating EGFR mutations. If EGFR mutation is negative or unknown, the recommendation favors cytotoxic chemotherapy. $\underline{32}$

A retrospective study investigated the initial impact of erlotinib or gefitinib versus chemotherapy on the risk of CNS progression in patients with EGFR mutations. One hundred fifty-five patients were considered (EGFR-TKI $n=101$, chemotherapy $n=54$ ). The HR of CNS progression for EGFRTKIs versus chemotherapy was $0.56(95 \% \mathrm{CI}, 0.34-0.94)$. If prospectively validated these data indicate that the treatment with EGFR-TKIs prevent CNS metastases in NSCLC with EGFR mutations. $\underline{80}$

In all studies with EGFR-TKI, it was observed that inevitably, despite the significant improvement in PFS and OS, all patients develop resistance. Mutations in the tyrosine kinase domain that render tumors resistant to erlotinib and gefitinib are the most common mechanism of resistance. The threonine-790-methionine (T790M) point mutation was identified in about half of the patients whose disease progressed during EGFR-TKI therapy and is rarely detected in untreated patients. Other mechanisms of resistance include c-MET overexpression (15\%-20\% of cases), in-frame duplications and/or insertion in exon 20 (5\% of the cases), and unknown mechanisms, which account for about $25 \%-30 \%$. $\underline{\text { and }} \underline{\underline{82}}$

Irreversible inhibitors of EGFR are a class of agents with the potential to overcome EGFR-TKI resistance. Afatinib (BIBW2992) is an irreversible ErbB-family blocker with potent activity against NSCLC harboring activating EGFR mutations and/or the gatekeeper mutation T790M, albeit at lower potency. It has been recently evaluated in several clinical trials with promising results. $\underline{83}$, $\underline{84}$ and $\underline{85}$ The LUX-Lung 3 was a phase III trial of afatinib versus CP as first-line treatment for 
patients with advanced adenocarcinoma harboring EGFR-activating mutations. Patients treated with afatinib had a median PFS, the primary endpoint of the study, of 11.1 versus 6.9 months for chemotherapy (HR 0.58; $P=.0004)$. ORR was also significantly higher with afatinib $(56 \% v 23 \%$, $P<.001)$, reporting a consistent delay in time to deterioration of cancer-related symptoms.

Recently the results of LUX-Lung 6 have been presented. This study compared the safety and efficacy of first-line afatinib versus gemcitabine plus cisplatin (GC) in Asiatic patients with EGFR mutation-positive tumors. Following central testing for EGFR mutations, 364 patients were randomized $2: 1$ to daily afatinib $40 \mathrm{mg}$ or GC $\left(1,000 \mathrm{mg} / \mathrm{m}^{2}\right.$ day $1,8+75 \mathrm{mg} / \mathrm{m}^{2}$ every 21 days intravenously up to six cycles). PFS, the primary endpoint of the study, was significantly prolonged with afatinib compared with GC (median PFS $11.0 v 5.6$ months, HR .28, $P<.0001$ ). Objective response $(66.9 \% \vee 23.0 \%, P<.0001)$ and disease control $(92.6 \% \vee 76.2 \%, P<.0001)$ rates were significantly higher with afatinib. Patient reported-outcomes (PROs) showed significantly better control of cancer-related dyspnea, cough, and pain with afatinib. Adverse events in both arms were as expected, with a more favorable safety profile with afatinib ( $\underline{\text { Table } 1}) . \underline{86}$

A phase II trial of afatinib versus gefitinib as first-line treatment (LUX-lung 7) in advanced NSCLC is currently recruiting patients with $E G F R$ activating mutations. $\underline{87}$

Another oral pan-HER inhibitor, dacomitinb (PF-00299804) with affinity for EGFR, HER2, and HER4, also has shown activity in NSCLC. A multinational, multicenter, randomized, open-label, phase 3 study comparing the efficacy and safety of dacomitinib to gefitinib is currently enrolling patients with locally advanced or metastatic NSCLC with EGFR-activating mutations having as

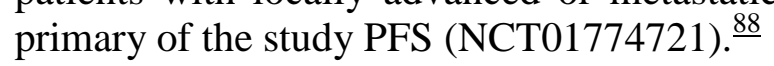

The different generations TKI and new agents in development, including EGFR-TKI agents against T790 mutation are summarized in Table 2.

Table 2.

Different Generations of EGFR Kinase Inhibitors

\begin{tabular}{|l|l|l||}
\hline First Generation & Second Generation & Third Generation (mutant-selective) \\
\hline \hline Gefitinib & XL647 & WZ4002 \\
\hline Erlotinib & Afatinib & CO-1686 \\
\hline \hline Lapatinib & Icotinib & AP26113 \\
\hline Canertinib & Neratinib & TAS-2913 \\
\hline \hline & Dacomitinib & AZD9291 \\
\hline \hline & & Z650 \\
\hline
\end{tabular}

\section{Monoclonal Antibodies Anti-EGFR}

Cetuximab is a chimeric monoclonal antibody that selectively binds the extracellular domain of the EGFR on the tumor cells and inhibits the receptor-associated tyrosine kinase activation. $\underline{89}$ and $\underline{90} \mathrm{~A}$ handful of randomized trials have evaluated the addition of cetuximab to chemotherapy, with two completed phase III trials. $\underline{.1}, \underline{92}, \underline{93}$ and $\underline{94}$ The First-Line Erbitux in Lung Cancer (FLEX) ${ }^{77}$ trial enrolled 1,125 patients with EGFR-expressing tumors randomized to receive cisplatin $80 \mathrm{mg} / \mathrm{m}^{2}$ day 1 and vinorelbine $25 \mathrm{mg} / \mathrm{m}^{2}$ days 1 and 8 (each cycle repeated every 3 weeks for up to six cycles) or the same chemotherapy plus cetuximab. OS was modestly improved with cetuximab (11.2 v 10.1 months; HR $0.871 ; P<.044)$. The response rate was also improved $(36 \% v 29 \%$; $P<.01)$. PFS was 4.8 months in both arms. The marginal OS benefit was observed in all histologic subgroups and there was no difference in quality of life between the study arms, although 
compliance with serial quality-of-life questionnaires was low. The main cetuximab-related toxicity was acne-like rash, which occurred in $10 \%$ of patients enrolled in the trial. Comparable results were observed in another trial, evaluating the addition of cetuximab to carboplatin plus paclitaxel or docetaxel. Three separate meta-analyses evaluated data from these two phase III trials and from other two randomized phase II trials comparing chemotherapy \pm cetuximab $\underline{95}, \underline{96}$ and $\underline{97}$ (Table 3 ). Among the 2,018 considered patients (1,003 in the cetuximab arm and 1,015 in the control arm), those treated with cetuximab had a $9 \%$ reduction in the risk of disease progression (HR 0.91; $P<.06$ ), a $13 \%$ reduction in the risk of death (HR $0.87 ; P<.004)$, and an approximately $50 \%$ increase in ORR $(P<.0001) .{ }^{75}$ The combination of cetuximab plus chemotherapy induced more grade $3 / 4$ rash $(5.2 \% \vee 1 \%, P<.000)$, diarrhea $(2.3 \% v 1.1 \%, P<.003)$, neutropenia $(19.5 \% v 16.1 \%, P<.029)$, and infusion reactions $(3.9 \% v 0.9 \%, P<.000)$.

Table 3.

Clinical Trials of Cetuximab and Chemotherapy Combination Versus Chemotherapy Alone

\begin{tabular}{|c|c|c|c|c|c|}
\hline Study & Phase & \begin{tabular}{|c|} 
Trial \\
Size (n)
\end{tabular} & Treatment & $\begin{array}{l}\text { Median PFS } \\
(\text { mo })\end{array}$ & $\begin{array}{l}\text { Median OS } \\
\quad(\mathbf{m o})\end{array}$ \\
\hline \begin{tabular}{|l} 
Butts et al \\
$(2007)^{94}$
\end{tabular} & |II & 65 & $\begin{array}{l}\text { Cis or } \mathrm{Carbo} / \mathrm{Gem} / \mathrm{Cet} \\
v \text { Cis or } \mathrm{Carbo} / \mathrm{Gem}\end{array}$ & $5.09 \vee 4.21$ & $12.0 \vee 9.3$ \\
\hline \begin{tabular}{|l}
$\begin{array}{l}\text { Rosell et al } \\
(2008)^{95}\end{array}$ \\
\end{tabular} & |II & 86 & $\begin{array}{l}\text { Cis/Vino/Cet } v \\
\text { Cis/Vino }\end{array}$ & $5.0 \vee 4.6$ & $8.3 v 7.3$ \\
\hline \multirow{3}{*}{$\begin{array}{l}\text { Pirker et al } \\
(2009) \\
\text { FLEX }^{96}\end{array}$} & \multirow{3}{*}{ III } & 1125 & \multirow{3}{*}{\begin{tabular}{|l} 
Cis/Vino/Cet $v$ \\
Cis/Vino
\end{tabular}} & \multirow{3}{*}{$\mid \begin{array}{l}4.8 v 4.8 \mathrm{HR}= \\
0.943(0.825- \\
1.77) P=.39 \mathrm{~ns}\end{array}$} & \multirow{3}{*}{\begin{tabular}{|l}
$11.3 v 10.1 \mathrm{HR}$ \\
$=0.87(0.76-$ \\
$0.996) P=.044$
\end{tabular}} \\
\hline & & $\begin{array}{l}557 \text { Cet } \\
\text { arm }\end{array}$ & & & \\
\hline & & \begin{tabular}{|l}
568 \\
Control \\
arm \\
\end{tabular} & & & \\
\hline \multirow{3}{*}{$\begin{array}{l}\text { Lynch et al } \\
(2010) \\
\text { BMS099 }^{97}\end{array}$} & \multirow{3}{*}{ III } & 676 & \multirow{3}{*}{$\begin{array}{l}\text { Carbo/pacli or } \\
\text { Doce/Cet } v \text { Carbo/pacli } \\
\text { or Doce/Cet }\end{array}$} & \multirow{3}{*}{$\begin{array}{l}4.40 \vee 4.24 \mathrm{HR} \\
=0.9(0.76- \\
1.07) P=.236 \\
\text { ns }\end{array}$} & \multirow{3}{*}{$\begin{array}{l}9.69 \vee 8.38 \mathrm{HR} \\
=0.89(0.75- \\
1.05) P=.169 \\
\text { ns }\end{array}$} \\
\hline & & $\begin{array}{l}338 \text { Cet } \\
\text { arm }\end{array}$ & & & \\
\hline & & $\begin{array}{l}338 \\
\text { Control } \\
\text { arm }\end{array}$ & & & \\
\hline
\end{tabular}

Abbreviations: Cis, cisplatin; Gem, gemcitabine; Carbo, carboplatin; Pacli, paclitaxel; Doce, docetaxel; Vino, vinorelbine; Cet, cetuximab; HR,hazard ratio; ns, not significant; OS, overall survival; PFS, progression-free survival.

In vitro data indicate that high levels of EGFR expression correlate with sensitivity to cetuximab,,$\underline{90}$ and $\underline{99}$ but a retrospective analysis of the FLEX study suggested that EGFR protein expression by immunohistochemistry is an inadequate predictor of the efficacy of EGFR-targeted therapy. Immunohistochemistry (IHC) measurement of EGFR intensity and frequency on tumor cells was used to generate, on a continuous scale of 0-300, an EGFR IHC score for each assessable patient study in order to investigate whether tumor EGFR expression levels were associated with a predictive role. Treatment outcomes were analysed in patients with low $(<200)$ and high $(\geq 200)$ EGFR IHC scores, representing $69 \%$ and $31 \%$ of evaluable patients, respectively. $\frac{100}{}$ For patients with a high EGFR IHC score, median OS was longer in the chemotherapy plus cetuximab arm than in the control arm (12.0 $v 9.6$ months, respectively; HR 0.73, $P=.011)$, without significant increase in cetuximab-related side effects. No corresponding survival benefit was observed in the group of patients with low EGFR IHC score (median OS of $9.8 v 10.3$ months, respectively; HR 0.99, $P=$ 
.88). EGFR expression level was not predictive at all of cetuximab benefit in first-line treatment of recurrent/metastatic squamous cell carcinoma of the head and neck (EXTREME) and K-ras wildtype metastatic colorectal cancer (CRYSTAL). $\underline{101}$

Based on existing inconsistent evidence cetuximab is currently not licensed for the treatment of advanced NSCLC even if cetuximab is recommended in combination with chemotherapy based on a lower level of evidence by the National Comprehensive Cancer Network practice guidelines for advanced/metastatic NSCLC..$^{102}$

Nevertheless, EGFR remains a important target for molecularly based therapies and currently another fully humanized monoclonal antibody targeting the EGFR extracellular domain III, necitumumab, is under investigation in two large phase III studies having the potential benefit of lower hypersensitivity reaction risk compared with cetuximab and also equivalent antibodydependent cell-mediated cytotoxicity. $\frac{103}{2}$ Recently the phase III study evaluating the addition on necitumumab to pemetrexed and cisplatin in non-squamous NSCLC was prematurely closed due to concerns about the risk of thromboembolic events in the experimental arm. $\frac{104}{}$ Accrual in the phase III trial of necitumumab in combination with gemcitabine and cisplatin in squamous NSCLC is completed. $\underline{105}$

\section{Anaplastic Lymphoma Kinase Inhibitors}

In NSCLC the role of targeted therapies has been further reinforced with the identification of the EML4-ALK (anaplastic lymphoma kinase) fusion gene, a genetic abnormality detected in the 4\%$6 \%$ of the adenocarcinomas of the lung, $\frac{106}{2}$ and the concomitant identification of a targeted agent, crizotinib, which is highly active in ALK-translocated tumors. ALK gene rearrangement is associated with specific clinical-pathological features, including male sex, young age, absent or minimal smoking history, adenocarcinoma histology, and usually mutual exclusivity between EML4-ALK and EGFR and KRAS mutations. $\underline{107}, \underline{108}$ and 109

Crizotinib is a MET inhibitor that also has activity on ALK and c-ROS1 oncogene (ROS1) pathways. It was first studied in humans in a phase I/II study (PROFILE 1001), with a standard dose-escalation pharmacokinetic schema followed in a second stage by clinical efficacy assessment. Preliminary results from the phase I study clearly demonstrated clinically relevant tumor shrinkage

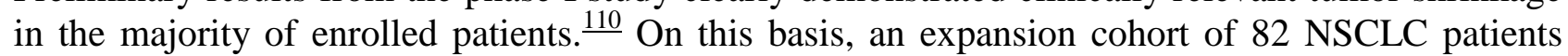
harboring the ALK rearrangement were enrolled to receive the recommended dose of crizotinib 250 mg twice daily. The ORR was 57\% (46 partial responses and one complete response). An additional $33 \%$ of patients had stable disease at the 8 -week assessment. $\frac{111}{1}$ An update of this study confirmed a ORR of $61 \%$ and the median PFS was 10 months. ${ }^{112}$ Based on the encouraging response rate of the phase I study, a large multicenter second-line study and beyond in ALK-positive NSCLC patients was performed. Patients characteristics largely corresponded to those of the previous study and the ORR was of $51 \% .113$ In both the phase I and phase II trials, the majority of responses was achieved during the first 8 weeks of treatment and duration of response was 48.1 and 41.9 weeks, respectively. Patients included in the phase I trial had a survival probabilities at 6 and 12 months of $90 \%$ and $81 \%$, respectively. Crizotinib gained approval by the US Food and Drug Administration (FDA) in August 2011 for any line of treatment in locally advanced or metastatic NSCLC, ALKpositive based on the outcome in terms of response rate of the abovementioned studies.

The high level of activity of crizotinib in ALK-positive NSCLC patients has been recently confirmed in a phase III study evaluating crizotinib versus pemetrexed or docetaxel as second-line treatment. The study met its primary endpoint demonstrating the superiority of crizotinib over the standard chemotherapy in prolonging PFS ( $7.7 v 3.0$ months, respectively; HR $0.49, P<.0001)$. ORR was significantly higher in patients treated with crizotinib $(65 \% v 20 \%, P<.0001)$ and the safety profile was acceptable. An interim analysis of OS showed no significant improvement with 
crizotinib as compared with chemotherapy (HR 1.02; $P=.54$ ). Better control of disease-related symptoms and improvement in quality of life have been reported with crizotinib. 114

As already described, thymidylate synthase (TS) level may predict the sensitivity to pemetrexedbased chemotherapy in different histological subtypes of NSCLC, being inversely correlated with pemetrexed efficacy. A recent study evaluating the role of pemetrexed-based chemotherapy in ALK-positive NSCLC patients, showed lower TS levels than the median values in unselected NSCLC. A low TS level has been observed in almost $83 \%$ of the evaluated cases $(P=.039)$ and the few ALK-positive NSCLC patients with high TS levels had poorest survival outcome. $\stackrel{115}{\text { These }}$ findings suggest that differences in TS expression levels in ALK-positive NSCLC patients may predict the differential responses to pemetrexed but also justify the major efficacy of pemetrexed compared to docetaxel in this subset of patients, as observed in the PROFILE 1007 trial.

The phase III trial PROFILE 1014 (NCT01154140) is currently the only study actively recruiting patients for the evaluation of crizotinib versus cisplatin or carboplatin plus pemetrexed as first-line treatment for previously untreated ALK-positive non-squamous NSCLC patients. The primary endpoint of the study is PFS, while ORR and OS are secondary endpoints. A superiority phase III trial with the same schedule of treatment has been designed for the East-Asian population, but the study is not yet open for accrual. 116

Although there are clinical-pathological features associated with ALK rearrangement they do not properly select patients for ALK inhibitors and, consequently, molecular testing is mandatory. There are three methods of detecting ALK rearrangement: the fluorescence in situ hybridization (FISH) break-apart assay, IHC, and reverse-transcriptase polymerase chain reaction (RT-PCR). Currently FISH is the gold standard and is the approved companion diagnostic test (Vysis ALK break apart FISH probe kit; Abbott Molecular, USA) by the US FDA. $\underline{117}, \underline{118}$ and $\underline{119}$

Several second-generation ALK inhibitors are under development and some are more potent and selective than crizotinib in terms of higher response rates or activity in patients who have acquired resistance to crizotinib. LDK378 is being developed as an alternative to crizotinib, based on increased potency and specificity.

In a phase I study, LDK378 was investigated in 123 ALK-positive patients with NSCLC $\frac{120}{}$ and the ORR in the 114 evaluable patients treated at $400 \mathrm{mg} / \mathrm{d}$ or more was $58 \%$. Activity was essentially the same in crizotinib-resistant and crizotinib-naïve patients, 57\% and 60\%, respectively. The median PFS and median duration of response (DOR) were 8.6 and 8.2 months, respectively. Treatment with LDK378 was reasonably tolerated. ${ }^{121}$ Two phase III trials are planned in ALKpositive NSCLC: in the first study LDK378 will be compared with single-agent chemotherapy after progression on a platinum based doublet and on crizotinib, $\frac{122}{2}$ while the second study in first-line treatment will compare LDK378 with a platinum-based doublet. $\underline{\underline{123}}$

CH5424802 is another potent selective orally available ALK inhibitor. In a multicenter, phase I/II study, 46 patients with ALK-positive NSCLC were treated with CH5424802 in the phase II portion of the study at the dose level of $300 \mathrm{mg}$ twice daily; none had received prior treatment with an ALK inhibitor. An objective response was observed in $93 \%$ of the patients, including two complete and 41 partial responses. $\frac{124}{}$

AP26113 is a TKI that potently inhibits mutant activated forms of ALK-positive and EGFRmutated tumors, and TKI-resistant forms including L1196M (ALK) and T790M (EGFR). AP26113 does not inhibit native EGFR. Currently a phase I/II open-label multicenter study is ongoing in patients with advanced malignancies (except leukemia) refractory to available therapies or for whom no standard treatment exists. AP26113 has promising anti-tumor activity in ALK-positive patients, with initial evidence of activity in EGFR-mutated patients, and is generally well tolerated. Phase II will be initiated after the recommended phase II dose will be defined in four different 
cohorts: crizotinib-naïve NSCLC; crizotinib-resistant NSCLC; EGFR TKI-resistant NSCLC; and other tumors $\underline{125}$ (Table 4$)$.

Table 4.

Second-Generation ALK Inhibitors

\begin{tabular}{|l|l|l|l|l|l|l||}
\hline ALK Inhibitors & Phase & n & ORR (n) & ORR (\%) & \multicolumn{1}{|c|}{ PFS } \\
\hline \hline LDK378 & I & 88 & 62 & 79 & 8.6 mo (95\% CI. 4.3-19.3) \\
\hline CH5424802 & I/II & 46 & 43 & 93.5 & - \\
\hline \hline AP26113 & I/II & 18 & 10 & 56 & - \\
\hline
\end{tabular}

Abbreviations: ORR, objective response rate; PFS, median progression-free survival.

\section{Early Palliative Care}

The symptom burden of patients with lung cancer is extensive and includes loss of appetite, dyspnea, and other symptoms that lead to decreased quality of life. A landmark study examined the benefit of early palliative care integrated with standard oncologic care versus standard oncologic care and palliative care only "as needed" on patient-reported outcomes, the use of health services, and the quality of end-of-life care among patients with metastatic NSCLC. The study was a prospective, nonblinded, randomized, controlled trial of outpatients conducted at a single center. Quality-of-life scores improved significantly in patients assigned to intervention compared with standard care. A 2.7-month difference in median survival $(P=.02)$ in favor of the group assigned to early palliative care was also observed, although survival was not a primary end point of the trial. This outcome needs to be validated in future studies. $\frac{126}{}$

\section{Second-Line Treatment}

\section{Single Agents}

Although cytotoxic chemotherapy and/or molecularly targeted agents as first-line treatments may delay disease progression and prolong survival, almost all of patients develop progressive disease and require additional therapies. The choice of treatment at relapse or progression depends on PS, comorbidity, histology, molecular characteristics, and, obviously, patient preference. Second-line therapy should be considered in patients with a good PS with clinical or radiological progression because this approach is associated with symptom palliation and increased survival in selected patients. $\frac{127}{2}$ and $\frac{128}{2}$ The benefit of second-line treatment also affects the outcome with first-line therapy. In a systematic review it was shown that post-progression survival is highly associated with OS for first-line chemotherapy, whereas PFS is only moderately associated with OS..$\underline{129}$

Single-agent docetaxel or pemetrexed and erlotinib are currently registered options. Other cytotoxic agents that are active as initial therapy also may have activity, but they have not been compared in randomized trials in previously treated patients with either best supportive care (BSC) or approved agents. $\frac{130}{}$

Supportive evidence for the approval of docetaxel as second-line therapy came from a couple of small phase III studies. $\frac{131}{2}$ and $\frac{132}{2}$ Although the every-3-week schedule of docetaxel is considered a standard of care recent data indicate the weekly schedule $\left(33.3 \mathrm{mg} / \mathrm{m}^{2}\right.$ to $40 \mathrm{mg} / \mathrm{m}^{2}$ for 6 weeks followed by a 2 -week rest) as an equally effective treatment but less toxic as clearly concluded by a meta-analysis. ${ }^{133}$ In a pivotal phase III study pemetrexed demonstrated to be non-inferior to docetaxel in terms of efficacy with a toxicity profile favoring pemetrexed. $\frac{134}{2}$ Retrospective data 
showed a differential activity of pemetrexed by histology with better survival with pemetrexed in patients with non-squamous histology (9.3 months $v 8$ months; $P \leq .048)$, whereas patients with squamous cell histology did better with docetaxel ( 7.4 months $v 6.2$ months; $P<.018)$. $\underline{135}$ and $\underline{136}$

Few studies have evaluated the combination of two cytotoxic agents in second-line and all these trials have failed to demonstrate superiority of the two-drug combination over docetaxel. $137, \underline{138}, \underline{139}$, $\underline{140}, \underline{141}$ and 142

In the second-/third-line setting erlotinib in a phase III study in chemotherapy-refractory patients, without limitation for EGFR status and histology, was demonstrated to be modestly superior to placebo. The ORR to erlotinib was $8.9 \%$, with an additional $36 \%$ of patients achieving stable disease. There was a significant improvement in PFS $(2.2 v 1.8$ months; HR $0.61 ; P=.001)$ and median survival time $(6.7 \vee 4.7$ months; HR $0.70 ; P=.001)$ favoring erlotinib. The effect of erlotinib on survival was similar across most of the considered subsets. Never-smokers and patients with EGFR-positive tumors had the larger survival benefit. $\underline{143}$

In a similar study, gefitinib versus placebo failed to demonstrate improved survival in truly chemotherapy-refractory patients (ISEL trial). ${ }^{71}$ However, the subset of Asian origin showed significant improvement in survival.

In a phase IIb/III trial in stage IIIB/IV patients with adenocarcinoma who had received one or two previous chemotherapy regimens and with disease progression after at least 12 weeks of treatment with reversible EGFR-TKIs, afatinib was tested against placebo. Although there was no benefit in terms of OS (10.8 $v 12.0$ months; HR 1.08) median PFS was longer in the afatinib arm (3.3 $v 1.1$ months; HR $0.38 ; 95 \% \mathrm{CI}, 0.31-0.48)$, as well as more patients reached an objective response $(29 v$ 1 patient). $\underline{83}$

Only one small randomized phase II study compared gefitinib with erlotinib in the this setting in 96 patients who failed to respond to first-line chemotherapy and had either EGFR mutation or at least two out of three clinical factors associated with a higher incidence of EGFR mutations. Both gefitinib and erlotinib showed activity and tolerable toxicity profiles. $\frac{144}{4}$

Several randomized studies that compared an EGFR-TKI versus chemotherapy in unselected or EGFR wild-type patients are summarized in Table 5 and Table 6. All of these studies indicate a marginal or detrimental effect of EGFR TKIs on PFS, especially in EGFR wild-type patients, without registering any difference in terms of OS. $\underline{75}, \underline{76}, \underline{77}, \underline{78}, \underline{79}, \underline{80}, \underline{81}, \underline{82}$ and $\underline{83}$ This information is fully consistent with the concept of the superior efficacy of EGFR-TKIs in EGFR-mutant tumors even in the context of additional lines of therapy.

Table 5.

Randomized Trials Comparing EGFR-TKI Versus Chemotherapy in Advanced NSCLC in EGFR Unselected Patients

\begin{tabular}{|c|c|c|c|c|c|c|}
\hline Trial & Regimen & $\mathbf{n}$ & \begin{tabular}{|c}
$\begin{array}{c}\text { Median PFS } \\
(\mathrm{mo})\end{array}$ \\
\end{tabular} & $\begin{array}{c}\text { HR }(95 \% \\
\text { CI }) \\
\end{array}$ & \begin{tabular}{|c|}
$\begin{array}{c}\text { Median OS } \\
\text { (mo) }\end{array}$ \\
\end{tabular} & \begin{tabular}{|c|} 
HR (95\% \\
CI) \\
\end{tabular} \\
\hline \multirow[t]{2}{*}{ INTEREST } & Gefitinib & 733 & 2.2 & \multirow{2}{*}{$\begin{array}{l}1.04(0.93- \\
1.18)\end{array}$} & 7.6 & $\begin{array}{l}1.02(0.91- \\
1.15)\end{array}$ \\
\hline & Docetaxel & 733 & 2.7 & & 8.0 & \\
\hline \multirow[t]{2}{*}{ V15-32 } & Gefitinib & 245 & 2.0 & \multirow{2}{*}{$\begin{array}{l}0.90(0.72- \\
1.12)\end{array}$} & 11.5 & $\begin{array}{l}1.12(0.89 \\
1.40)\end{array}$ \\
\hline & Docetaxel & 244 & 2.0 & & 14.0 & \\
\hline
\end{tabular}




\begin{tabular}{|c|c|c|c|c|c|c|}
\hline Trial & Regimen & $\mathbf{n}$ & $\begin{array}{c}\text { Median PFS } \\
(\mathrm{mo})\end{array}$ & \begin{tabular}{|c|} 
HR $(95 \%$ \\
CI) \\
\end{tabular} & \begin{tabular}{|c}
$\begin{array}{c}\text { Median OS } \\
\text { (mo) }\end{array}$ \\
\end{tabular} & \begin{tabular}{|c} 
HR $(95 \%$ \\
CI) \\
\end{tabular} \\
\hline \multirow{2}{*}{ ISTANA } & Gefitinib & 82 & $\mid 3.3$ & \multirow{2}{*}{$\begin{array}{l}0.73(0.53- \\
1.00)\end{array}$} & 14.1 & $\begin{array}{l}0.87(0.61- \\
1.24)\end{array}$ \\
\hline & Docetaxel & 79 & 2.4 & & 12.2 & \\
\hline \multirow{2}{*}{ HORG } & Erlotinib & 166 & 3.6 & \multirow{2}{*}{ NR } & 7.9 & NR \\
\hline & Pemetrexed & 166 & 2.7 & & 8.9 & \\
\hline \multirow{2}{*}{ TITAN } & Erlotinib & $\mid 203$ & $\mid 1.4$ & \multirow{2}{*}{$\begin{array}{l}1.19(0.97- \\
1.46)\end{array}$} & 5.3 & $\begin{array}{l}0.96(0.78 \\
1.19)\end{array}$ \\
\hline & Docetaxel/pemetrexed & 221 & 2.0 & & 5.5 & \\
\hline \multirow[t]{2}{*}{ DELTA } & Erlotinib & $\|151\|$ & $\mid 2.0$ & \multirow{2}{*}{$\begin{array}{l}1.22(0.97- \\
1.55)\end{array}$} & 14.8 & $\begin{array}{l}0.91(0.68 \\
1.22) \\
\end{array}$ \\
\hline & Docetaxel & 150 & 3.2 & & 12.2 & \\
\hline
\end{tabular}

Abbreviations: PFS, progression-free survival; HR, hazard ratio; OS, overall survival; CI, confidence interval; NR, not reached.

Table 6.

Randomized Trials Comparing EGFR-TKI Versus Chemotherapy in Advanced NSCLC in EGFR Wild-Type Patients

\begin{tabular}{|c|c|c|c|c|c|c|}
\hline Trial & Regimen & $\mathbf{n}$ & $\begin{array}{c}\text { Median PFS } \\
(\mathrm{mo})\end{array}$ & \begin{tabular}{|c|} 
HR $(95 \%$ \\
CI)
\end{tabular} & $\begin{array}{c}\text { Median OS } \\
\text { (mo) }\end{array}$ & \begin{tabular}{|c|} 
HR $(95 \%$ \\
CI)
\end{tabular} \\
\hline \multirow[t]{2}{*}{ INTEREST } & Gefitinib & 106 & 1.7 & \multirow{2}{*}{$\begin{array}{l}1.24(0.94- \\
1.64) \\
\end{array}$} & 6.4 & \multirow{2}{*}{$\begin{array}{l}1.02(0.78- \\
1.33)\end{array}$} \\
\hline & Docetaxel & 123 & 2.6 & & 6.0 & \\
\hline \multirow[t]{2}{*}{ TITAN } & Erlotinib & 75 & $\mid 1.4$ & \multirow{2}{*}{$\begin{array}{l}1.25(0.88- \\
1.78)\end{array}$} & 6.4 & $\begin{array}{l}0.85(0.59 \\
1.22)\end{array}$ \\
\hline & Docetaxel/Pemetrexed & 74 & 2.0 & & 4.5 & \\
\hline \multirow[t]{2}{*}{ TAILOR } & Erlotinib & 107 & $\mid 2.4$ & $\begin{array}{l}1.45(1.08- \\
1.92)\end{array}$ & & \multirow[t]{2}{*}{ N.A. } \\
\hline & Docetaxel & 104 & 3.4 & & & \\
\hline \multirow[t]{2}{*}{ DELTA } & Erlotinib & 109 & 1.3 & \multirow{2}{*}{$\begin{array}{l}1.45(1.09- \\
1.94)\end{array}$} & 9.0 & \multirow{2}{*}{$\begin{array}{l}0.98(0.69 \\
1.39)\end{array}$} \\
\hline & Docetaxel & 90 & 2.9 & & 10.1 & \\
\hline
\end{tabular}

Abbreviations: PFS, progression-free survival; HR, hazard ratio; OS, overall survival; CI, confidence interval; NA, not available.

Heat shock protein 90 (Hsp90) is a molecular chaperone required for the stability of a number of conditionally activated and/or expressed signalling proteins, as well as multiple mutated, chimeric, and overexpressed signalling proteins, that promote cancer cell growth and/or survival. Ganetespib is a novel, second-generation Hsp90 inhibitor with a favorable safety profile, active as single agent especially in ALK-positive NSCLC. ${ }^{145}$ Based on synergistic preclinical interactions between docetaxel and ganetespib, a phase II study enrolled 255 adenocarcinoma patients previously treated with one line of therapy. Co-primary endpoints were PFS in patients with elevated lactate dehydrogenase (LDH) or in tumors harboring KRAS mutations. The study demonstrated that ganetespib in combination with docetaxel had an acceptable safety profile with an improvement in OS and PFS compared to docetaxel alone. The improvements in OS and PFS were substantially enhanced in patients with a diagnosis of advanced disease $>6$ months and the observed improvement 
in survival does not appear to be associated with EGFR or KRAS mutational status. ${ }^{146}$ A phase III study in second line in patients with advanced adenocarcinoma progressing $>6$ months from diagnosis is currently ongoing.

A recent meta-analysis $\frac{147}{4}$ of randomized trials evaluated the efficacy and safety of single agent erlotinib versus different combinations of molecular targeted agents in second line. Eight eligible trials were identified, involving 2,417 patients. The intention-to-treatment (ITT) analysis demonstrated that combinations of targeted therapies significantly improved OS (HR 0.90, $P=$ $.024)$, PFS (HR 0.83, $P=.018$ ), and ORR (OR $1.35, P=.04)$. In the subgroup analyses based on type of studies, EGFR status and KRAS status there was a tendency to improve PFS and OS in combining targeted therapies, except that for patients with EGFR mutation or wild-type KRAS, which favored single-agent erlotinib. Additionally, grade 3 or 4 rash, fatigue, and hypertension were more frequently reported with combinations of targeted therapy. Based on the results of each individual studies included in the abovementioned meta-analysis, there is no convincing evidence supporting the use of combinations of targeted agents in second line, mainly because of the lack of OS benefit and for the higher toxicity profile of the combinations that reduce the trade-off between activity and toxicity,. The same conclusions may be applied to the combination of cytotoxic agents with a wide array of targeted therapies.

Lung cancer is a progressive and dynamic genetic process that leads to acquisition of several alternative escape mechanisms that overcome the simple drug interference on one or two pathways (eg, EGFR/VEGFR or EGFR/MET). For this reason it is mandatory to continuously search for specific predictive biomarkers with the goal to identify subtypes of NSCLC responsive to the different biological agents. The inclusion of unselected populations of NSCLC patients in clinical trials should be abandoned.

\section{Treatment Opportunities Beyond Second Line}

Treatment options for patients whose tumors have failed to respond to two or more conventional chemotherapy regimens are limited, with erlotinib and crizotinib being the only agents currently approved as third-line therapy for patients with advanced/metastatic NSCLC.

The efficacy of gefitinib and erlotinib as third-line therapy was assessed retrospectively through the Taiwan Cancer Registry and the National Insurance claim databases. Among 984 patients recruited, the two agents showed comparable OS (median, $10.2 v 9.9$ months; $P=.524$ ) and TTF (median, 5.5 $v 3.4$ months; $P=.103$ ). At multivariate analyses, both treatments had similar risk of overall mortality (adjusted HR 1.04, $P=.629$ ) and treatment failure (adjusted HR 0.94, $P=.417$ ).

Subgroup analyses based on age, tumor histology, and gender also did not reveal differences in OS and TTF. For patients who received gefitinib or erlotinib for more than 3 or 6 months, there was no difference in TTF, but patients who received erlotinib had longer OS. $\underline{148}$

The paucity of approved agents for third-line therapy and beyond constitutes an important unmet medical need. ${ }^{149}$ Several targeted agents, including some with multiple targets, have been or are currently being evaluated as third- and fourth-line therapy.

In a large study (ZEST) vandetanib, an orally administered inhibitor of VEGFR, EGFR, and RET, was compared with erlotinib after failure of one or two prior chemotherapy regimens. The study failed to show improvement in either PFS or OS. $\frac{150}{}$ Similarly in the ZEPHYR trial, which compared vandetanib with placebo after failure of one to two prior chemotherapy regimens, including a prior EGFR-TKI, vandetanib did not increase OS, although it significantly improved PFS (HR 0.6; $P<.0001)$, ORR $(2.6 \% v 0.7 \% ; P=.028)$, and disease control rate at 8 weeks $(30 \% v$ $16 \% ; P<.0001) .151$ 
Single-agent sorafenib, a raf kinase and angiogenesis inhibitor, was investigated in a phase II study in heavily pretreated patients (two or more lines of therapy) using a randomized discontinuation design. Patients received $400 \mathrm{mg}$ of sorafenib orally twice daily for two cycles (step 1). Responding patients continued on sorafenib, while progressing patients went off study. Patients with stable disease were randomized to receive placebo or sorafenib with a cross-over from placebo allowed upon progression. Two hundred ninety-nine patients were evaluable for step 1 and 81 eligible patients were randomized on step 2. The 2-month disease control rates after randomization were $54 \%$ and $23 \%$ for sorafenib and placebo, respectively $(P=.005)$. The HR for progression of step 2 significantly favored sorafenib and there was also a trend for an improved survival. $\stackrel{152}{\text { These data }}$ were the background for the subsequent double-blind, placebo-controlled, multicenter phase III study (MISSION), which assessed whether third-/fourth-line treatment with sorafenib plus best supportive care would improve OS relative to best supportive care plus placebo in patients with relapsed/refractory NSCLC of predominantly non-squamous histology. A total of 703 patients were randomized with baseline demographic data and prior treatments generally well balanced. Median OS was similar in the two groups, whereas PFS, TTF, ORR, and disease control rate were significantly greater in the sorafenib group. Rates of all and serious adverse events were higher in the experimental arm. $\frac{153}{}$ Based on these data, no further development of sorafenib in this setting has been planned.

Apatinib (YN968D1) is a multiple kinase inhibitor with in vitro activity against VEGFR-2, PDGFR-beta, c-Kit, and c-src. ${ }^{154}$ In addition, it counteracts the effects of multidrug resistance conferred by ABCB1 and ABCG2 proteins at concentrations lower than those associated with kinase inhibition. $\frac{155}{2}$ Results of a phase II randomized, placebo-controlled, study in patients with non-squamous NSCLC after two previous treatment regimens was conducted in China. Among 135 patients randomized to receive apatinib at the dose of $750 \mathrm{mg}$ or placebo orally once daily until disease progression or unacceptable toxicity, median PFS was 4.7 months for apatinib and 1.9 months for placebo (HR 0.28). Response rate and disease control rate were also significantly better in the experimental arm. Adverse events known to be associated with anti-angiogenetic multiple TKI agents were generally mild or moderate in severity and manageable. $\frac{156}{}$

Incorporation of genetic analysis for a better selection of treatments beyond second line is quite likely a future requirement at least in the context of clinical trials, but it yields additional and more complicated challenges and perspectives. This task may be particularly challenging in the secondand third-line settings, where the availability of tissue for molecular analysis is often limited and not routinely collected. $\frac{157}{}$

Even if at the present time repeat biopsies outside of a specific trial setting are not a requirement given the relative infrequency of clearly actionable targets with readily available treatments, it is equally important to recognize we have made huge progress in our understanding of molecular oncology that led to some of the new treatment options based on a greater emphasis on tissue collection and identifying relevant mutations.

\section{The Emerging Role Of Immunotherapy}

Despite the limited efficacy of immunotherapy in the treatment of lung cancer in the past and the various mechanisms that lung cancer can use to thwart the immune system attack, vaccines are currently being evaluated in phase III trials, and checkpoint inhibitors show potential promise in NSCLC. .158

A phase I trial of nivolumab, an anti-PD-1 antibody (BMS-936558) administered once every 2 weeks, included a large dose expansion cohort of patients with NSCLC. Patients with advanced NSCLC who had been previously treated with a prior platinum-containing regimen were eligible but could have received no more than five prior treatment regimens for their advanced disease. Besides being included in the dose-escalation portion of the trial, patients with NSCLC were 
randomly assigned to 1,3 , and $10 \mathrm{mg} / \mathrm{kg}$ to include equal numbers of squamous and non-squamous cell histology at each dose level. A total of 122 patients with NSCLC were enrolled, of whom 76 were assessable for response at the time of data analysis. The majority of patients with NSCLC were heavily pretreated; $55 \%$ of patients received at least three prior lines of therapy. Fourteen patients had objective responses (18\%). Responses were seen at all dose levels studied and in squamous as well as non-squamous histology. Interestingly, tumor PD-L1 expression may be associated with tumor response. Patients without tumor expression of PD-L1 had no documented tumor responses, but $36 \%$ of patients with tumor PD-L1 expression were objective responders. $\frac{159}{}$ Long follow-up data of this cohort of patients showed an encouraging sustained OS across

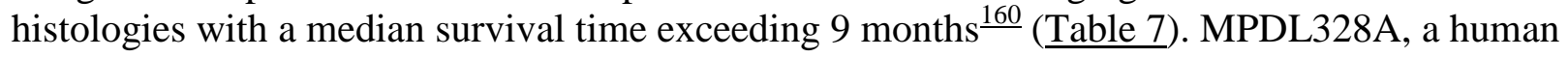
monoclonal antibody containing an engineered $\mathrm{Fc}$ domain designed to optimize efficacy and safety that targets PD-L1, blocking PD-L1 from binding its receptors, including PD-1 and B7.1 has been tested recently in a phase I expansion study in NSCLC. Early efficacy data indicate an ORR of $24 \%$ observed in squamous and non-squamous histology, including several responses with rapid tumor shrinkage. $\stackrel{161}{ }$ Preliminary data from a phase II study of nivolumab in combination with chemotherapy have been recently presented. $\underline{162}$

Table 7.

Phase I Trials of Anti-PD-1 and Anti-PD-L1 Antibodies in NSCLC

\begin{tabular}{|c|c|c|c|c|c|}
\hline Agents & Phase & Treatment & $\mathbf{N}$ & ORRs & $\begin{array}{c}\text { OS, mo } \\
(95 \% \mathrm{CI})\end{array}$ \\
\hline $\begin{array}{l}\text { Anti- } \\
\text { PD-1 } 160\end{array}$ & I & $\begin{array}{l}\text { Nivolumab in } \\
\text { previously treated } \\
\text { advanced NSCLC }\end{array}$ & $\mid 122$ & $\mid \begin{array}{l}16 \% \text { Non- } \\
\text { squamous } 15 \% \\
\text { Squamous } 19 \%\end{array}$ & \begin{tabular}{|l}
$9.6(7.4-$ \\
$13.7) 9.6$ \\
$(5.3-13.7)$ \\
$9.2(7.6-$ \\
NR)
\end{tabular} \\
\hline $\begin{array}{l}\text { Anti- } \\
\text { PD-1 } 162\end{array}$ & $\mathrm{I}$ & $\begin{array}{l}\text { BMS-936558 plus } \\
\text { platinum-doublets in } \\
\text { chemotherapy-naive } \\
\text { NSCLC }\end{array}$ & $\begin{array}{l}43 \text { A arm: } 12 \\
\text { (squamous) B arm: } \\
15 \text { (non-squamous) C } \\
\text { arm: } 16 \text { (3 squamous } \\
+13 \text { non-squamous) }\end{array}$ & $\mid 33 \%, 33 \%, 31 \%$ & - \\
\hline $\begin{array}{l}\text { Anti- } \\
\text { PD- } \\
\text { L1 } 161\end{array}$ & $\mathrm{I}$ & MPDL3280A & | 37 & $\begin{array}{l}\text { 24\% PD-L1 tumor } \\
\text { status-positive } \\
100 \%(4 / 4) \text { PD-L1 } \\
\text { tumor status- } \\
\text { negative } 15 \% \\
(4 / 26)\end{array}$ & - \\
\hline
\end{tabular}

Abbreviations: PT-doublet, platinum-based doublet chemotherapy with (A) nivolumab/gemcitabine/cisplatin or (B) nivolumab/pemetrexed/cisplatin; or (C) nivolumab/carboplatin/paclitaxel; ORR, objective response rate; OS, overall survival; CI, confidence interval.

\section{Systemic Treatment In The Elderly}

Based on the outcome of phase III studies $\frac{163}{16}$ and 164 single-agent vinorelbine or gemcitabine has been the recommended treatment for most patients with stage IV NSCLC who are aged 70-79 years. $\frac{31}{}$ Older fit patients are often considered unable to tolerate platinum-based systemic therapy. 
A retrospective analysis of ECOG 5592, a phase III trial in which chemotherapy-naive patients with stage IIIB or IV NSCLC were randomized to cisplatin plus either etoposide or paclitaxel, showed in elderly patients more treatment-related toxicity but comparable ORR and OS with the overall treated patients. $\frac{165}{}$ The combined assessment of six studies of the combination of docetaxel plus gemcitabine revealed no difference in efficacy according to age, but showed an increase in the incidence of mucositis in elderly patients. ${ }^{166}$ However, in a phase III trial (Multicenter Italian Lung Cancer in the Elderly Study) conducted in patients $\geq 70$ years old the combination of vinorelbine/gemcitabine did not show an advantage over single agent gemcitabine or vinorelbine in terms of quality of life and OS. $\underline{168}$

In a Japanese trial (JCOG 0207) 126 patients $\geq 70$ years with stage III/IV advanced NSCLC and a PS of $0-1$ were randomized to docetaxel $\left(20 \mathrm{mg} / \mathrm{m}^{2}\right)$ and cisplatin $\left(25 \mathrm{mg} / \mathrm{m}^{2}\right)$ weekly for 3 weeks every a 28-day cycle compared with docetaxel $\left(25 \mathrm{mg} / \mathrm{m}^{2}\right)$ alone with the same schedule. The trial stopped early at the second interim analysis because of a survival benefit favoring the combination in the subgroup of patients who were $70-74$ years of age (HR $0.23 ; P \leq .077$ ). The rate of grade $3 / 4$ neutropenia, anemia, and anorexia were higher in the combination arm. In those patients $\geq 75$ years of age, toxicity was higher without any OS benefit. $\stackrel{167}{ }$ Another Japanese study compared the same weekly schedule of cisplatin and docetaxel with docetaxel alone administered every 3 weeks in chemotherapy-naive patients $\geq 70$ years and PS $0-1$. This study failed to demonstrate any advantage of the combination over single agent. $\frac{168}{}$

The French multicenter randomized phase III trial (IFCT 0501) successfully compared a platinumbased combination versus single-agent therapy. $\frac{169}{}$ Carboplatin (area under the concentration curve [AUC] 6 on day 1) and paclitaxel $\left(90 \mathrm{mg} / \mathrm{m}^{2}\right.$ on days 1,8 , and 15 every 28 days) was compared with either vinorelbine $\left(25 \mathrm{mg} / \mathrm{m}^{2}\right.$ on day 8 every 21 days $)$ or gemcitabine $\left(1,150 \mathrm{mg} / \mathrm{m}^{2}\right.$ on days 1 and 8 every 21 days). ORR $(27 \% v 10 \%, P<.0001)$, median PFS $(6.0 v 2.8$ months, $P<.0001)$, and median survival time $(10.3 \vee 6.2$ months; HR $0.64 ; P<.001)$ were significantly longer in the combination compared with the single -agent arm. Toxicity was increased in the combination arm with higher rate of grade 3/4 neutropenia, febrile neutropenia, thrombocytopenia, anemia, and sensory neuropathy, as well as treatment-related deaths $(4.1 \%)$.

A subset analysis of a trial already mentioned demonstrated that in patients age $\geq 70$ years nabpaclitaxel plus carboplatin versus standard paclitaxel and carboplatin showed a significant increase in OS $(19.9 v 10.4$ months; $P=.009) . \stackrel{170}{ }$

In 2010, the Elderly Task Force of the European Organization of Research and Treatment of Cancer and Lung Cancer Group and the International Society for Geriatric Oncology published a systematic review on the treatment of NSCLC in elderly patients. It was recommended to consider two-drug combinations in selected elderly patients with a good PS and a lack of significant comorbidities. $\underline{171}$

\section{Systemic Treatment In Poor Performance Status Patients}

As in other cancers PS has a defined prognostic role in advanced NSCLC and in PS 2 patients median survival is 3-5 months with 1 -year survival<20\%. ${ }^{172}$ PS 2 patients usually account for a small proportion of patients enrolled in trials and for this reason the strength of existing recommendations for this type of patients is quite weak. $\frac{173}{2}$ The ECOG 1594 trial randomly assigned patients to one of four different platinum based double-agent chemotherapy regimens. It was observed an excessive rate of adverse events among PS 2 patients, which led to a hold on enrollment of these patients in the early phase of the study. This observation contributed to the exclusion of PS 2 patients from subsequent trials investigating platinum-based therapy. $\frac{174}{}$ The Cancer and Leukemia Group B (CALGB) 9730 trial was a phase III trial that compared carboplatin and paclitaxel to paclitaxel. PS 2 patients assigned to doublet experienced a significantly higher ORR, better median survival time, and a statistically significant higher 1-year OS rate. ${ }^{7}$ Furthermore 
a retrospective review confirmed that the combination of carboplatin and paclitaxel in PS 2 patients had a toxicity rate similar to that observed in PS $0-1$ patients. $\frac{175}{2}$ A combined analysis compared single-agent (gemcitabine or vinorelbine) versus carboplatin and paclitaxel and confirmed a higher ORR and median TTP with the combination without significant difference in OS. $\frac{176}{}$ A prospective phase III trial of carboplatin and gemcitabine compared with gemcitabine alone revealed a significantly higher ORR $(21.1 \%$ and $6.1 \%, P<.01)$, which did not translate in any statistically significant improvement in median PFS (3.8 and 2.7 months, $P=.14$ ) or OS (6.7 and 5.1 months, $P$ $=.24) .177$

More recently another phase III trial assessed carboplatin and pemetrexed with pemetrexed alone. Patients treated with doublet chemotherapy experienced a significantly higher ORR (24\% v 10.5\%, $P=.029$ ), longer PFS (HR 0.46; $P<.001$; median PFS $5.9 \vee 3.0$ months, respectively), and OS (HR $0.57 ; P<.001$; median OS $9.1 v 5.6$ months, respectively). $\frac{178}{}$

Limited amount of data are available for targeted agents. Erlotinib was compared with carboplatin and paclitaxel in first-line for patients with PS 2. This study showed a lower PFS and OS compared with chemotherapy. $\frac{179}{}$ A randomized trial comparing gefitinib versus placebo in patients not candidates for chemotherapy with PS 2-3 revealed no advantage in OS and PFS for patients receiving gefitinib. Only in the subgroup with FISH-positive EGFR was there a statistically significant advantage in PFS. $\frac{180}{}$

To date, no standard of care exists for patients with advanced NSCLC and PS 2; in these patients, clinical assessment and risk-benefit ratio must be taken into account in the choice of treatment.

\section{Conclusions}

Most of the newly diagnosed patients with NSCLC have metastatic disease and for these patients there are many new emerging treatment options currently in clinical trials aiming to further improve survival beyond the boundaries reached with cytotoxic chemotherapy. To date, histology as a surrogate marker and in the context of the different lines of therapy, has already influenced efficacy outcomes. Improvements have been made in extending survival in selected groups of patients with tumors harbouring specific genomic alterations without a significant impact on the overall population of patients with advanced NSCLC. Only the discovery through systematic search of homogeneous subgroups of tumours with the same genetic characteristics and the search for individualized approaches could represent the way to improve survival expectancy for these patients. Some progress has been made targeting two of the major biological pathways in lung cancer, the EGFR and VEGFR pathways, and deepening our knowledge about the mechanisms of tumor growth and differentiation mediated by these markers or associated molecules. EGFR-TKIs should be the preferred front line treatment choice for advanced patients with non-squamous tumors with EGFR-sensitizing mutations. For the minority of patients harboring $A L K$ gene rearrangements, the preferred treatment is represented by crizotinib. Second generation and more potent ALK inhibitors are currently in development and have already demonstrated activity in crizotinibresistant patients. For all other non-squamous NSCLC patients, the doublet of a platinum agent with pemetrexed or the triplet combination of carboplatin plus paclitaxel and bevacizumab are recommended treatment options. Standard of care for patients with advanced squamous cell carcinoma remains doublet chemotherapy. Second-line therapies include single-agent docetaxel, pemetrexed, and erlotinib. Re-challenge with the same combination doublet used in first line remains an experimental option that needs validation and may be eventually considered in extremely fit patients with a long-lasting tumor response or disease stabilization. Treatment options for patients whose tumors have failed to respond to two or more conventional chemotherapy regimens are limited; erlotinib and crizotinib are the only agents currently approved in many countries as third-line therapy for patients with advanced/metastatic NSCLC. Targeted agents in development may contribute to the unmet need in third line and beyond, and agents with multiple targets may have the potential for greater efficacy with acceptable toxicity profiles. Biomarker 
correlates will likely be the key to identifying those patients most likely to benefit from newer targeted agents.

\section{References}

$\underline{1}$

R. Siegel, D. Naishadham, A. Jemal

Cancer statistics

Ca Cancer J Clin, 62 (2012), pp. 10-29

$\underline{2}$

American Cancer Society. Lung cancer (non small cell). 2012:1-68.

http://www.cancer.org/acs/groups/cid/documents/webcontent/003115-pdf.

$\underline{3}$

Non-Small Cell Lung Cancer Collaborative Group

Chemotherapy in non-small cell lung cancer: a meta-analysis using updated data on individual patients

from 52 randomised clinical trials

Br Med J, 311 (1995), p. 899

$\underline{4}$

Non-Small Cell Lung Cancer Collaborative Group

Chemotherapy in addition to supportive care improves survival in advanced non-small-cell lung cancer: a systematic review and meta-analysis of individual patient data from 16 randomized controlled trials J Clin Oncol, 26 (28) (2008), p. 4617

$\underline{5}$

A.J. Wozniak, J.J. Crowley, S.P. Balcerzak, G.R. Weiss, C.H. Spiridonidis, L.H. Baker, et al.

Randomized trial comparing cisplatin with cisplatin plus vinorelbine in the treatment of advanced nonsmall-cell lung cancer: a Southwest Oncology Group study

J Clin Oncol, 16 (7) (1998), pp. 2459-2465

\section{$\underline{6}$}

A.B. Sandler, J. Nemunaitis, C. Denham, J. von Pawel, Y. Cormier, U. Gatzemeier, et al. Phase III trial of gemcitabine plus cisplatin versus cisplatin alone in patients with locally advanced or metastatic non-small-cell lung cancer

J Clin Oncol, 18 (1) (2000), pp. 122-130

$\underline{7}$

R.C. Lilenbaum, J.E. Herndon 2nd, M.A. List, C. Desch, D.M. Watson, A.A. Miller, et al.

Single-agent versus combination chemotherapy in advanced non-small cell lung cancer: the Cancer and Leukemia Group B (Study 9730)

J Clin Oncol, 23 (1) (2005), pp. 190-196

$\underline{8}$

K. Kelly, J. Crowley, P.A. Bunn Jr, C.A. Presant, P.K. Grevstad, C.M. Moinpour

Randomized phase III trial of paclitaxel plus carboplatin versus vinorelbine plus cisplatin in the treatment of patients with advanced non-small-cell lung cancer: a Southwest Oncology Group Trial

J Clin Oncol, 19 (2001), pp. 3210-3218

$\underline{9}$

T. Le Chevalier, G. Scagliotti, R. Natale, S. Danson, R. Rosell, R. Stahel, et al.

Efficacy of gemcitabine plus platinum chemotherapy compared with other platinum containing regimens in advanced non-small-cell lung cancer: a meta-analysis of survival outcomes

Lung Cancer, 47 (2005), pp. 69-80

$\underline{10}$

J.Y. Douillard, S. Laporte, F. Fossella, V. Georgoulias, J.L. Pujol, K. Kubota, et al.

Comparison of docetaxel- and vinca alkaloid-based chemotherapy in the first-line treatment of advanced non-small cell lung cancer: a meta-analysis of seven randomized clinical trials

J Thorac Oncol, 2 (2007), pp. 939-946

$\underline{11}$

F. Grossi, M. Aita, C. Defferrari, F. Rosetti, A. Brianti, G. Fasola, et al. 
Impact of third-generation drugs on the activity of first-line chemotherapy in advanced non-small cell lung cancer: a meta-analytical approach

Oncologist, 14 (2009), pp. 497-510

$\underline{12}$

A. Ardizzoni, L. Boni, M. Tiseo, F.V. Fossella, J.H. Schiller, M. Paesmans, et al.

Cisplatin-versus carboplatin-based chemotherapy in first-line treatment of advanced non-small-cell lung cancer: an individual patient data meta-analysis

J Natl Cancer Inst, 99 (2007), pp. 847-857

$\underline{13}$

J.H. Schiller, D. Harrington, C.P. Belani, C. Langer, A. Sandler, J. Krook, et al.

Comparison of four chemotherapy regimens for advanced non-small cell lung cancer

N Engl J Med, 346 (2002), pp. 92-98

$\underline{14}$

G.V. Scagliotti, F. De Marinis, M. Rinaldi, L. Crinò, C. Gridelli, S. Ricci, et al.

Phase III randomized trial comparing three platinum-based doublets in advanced non-small-cell lung

cancer

J Clin Oncol, 20 (2002), pp. 4285-4291

$\underline{15}$

F. Fossella, J.R. Pereira, J. von Pawel, A. Pluzanska, V. Gorbounova, E. Kaukel, et al.

Randomized, multinational, phase III study of docetaxel plus platinum combinations versus vinorelbine plus cisplatin for advanced non-small cell lung cancer: the TAX 326 study group

J Clin Oncol, 21 (2003), pp. 3016-3024

$\underline{16}$

C. Delbaldo, S. Michiels, N. Syz, J.C. Soria, T. Le Chevalier, J.P. Pignon

Benefits of adding a drug to a single-agent or a 2-agent chemotherapy regimen in advanced nonsmall-cell lung cancer: a meta-analysis

JAMA, 292 (2004), pp. 470-484

$\underline{17}$

G. Scagliotti, N. Hanna, F. Fossella, K. Sugarman, J. Blatter, P. Peterson, et al.

The differential efficacy of pemetrexed according to NSCLC histology: a review of two phase III studies

Oncologist, 14 (2009), pp. 253-263

$\underline{18}$

G.V. Scagliotti, P. Parikh, J. von Pawel, B. Biesma, J. Vansteenkiste, C. Manegold, et al.

Phase III study comparing cisplatin plus gemcitabine with cisplatin plus pemetrexed in chemotherapy-naive patients with advanced-stage non-small-cell lung cancer

J Clin Oncol, 26 (2008), pp. 3543-3551

$\underline{19}$

A.H. Calvert

Biochemical pharmacology of pemetrexed

Oncology (Williston Park), 18 (suppl 8) (2004), pp. 13-17

$\underline{20}$

M.A. Socinski, E.F. Smit, P. Lorigan, K. Konduri, M. Reck, A. Szczesna, et al.

Phase III study of pemetrexed plus carboplatin compared with etoposid plus carboplatin in chemotherapynaïve patients with extensive stage small cell lung cancer

J Clin Oncol, 27 (2009), pp. 4787-4792

$\underline{21}$

M.A. Socinski, G.M. Manikhas, D.L. Stroyakovsky, A.N. Makhson, S.V. Cheporov, S.V. Orlov, et al.

A dose finding study of weekly and every-3-week nab-Paclitaxel followed by carboplatin as first-line therapy in patients with advanced nonsmall cell lung cancer

J Thorac Oncol, 5 (2010), pp. 852-861

$\underline{22}$

M.A. Socinski, I. Bondarenko, N.A. Karaseva, A.M. Makhson, I. Vynnychenko, I. Okamoto, et al.

Weekly nab-paclitaxel in combination with carboplatin versus solvent-based paclitaxel plus carboplatin as first-line therapy in patients with advanced non-small-cell lung cancer: final results of a phase III trial

J Clin Oncol, 30 (2012), pp. 2055-2062

$\underline{23}$ 
R.S. Herbst, A. Onn, A. Sandler

Angiogenesis and lung cancer: prognostic and therapeutic implications

J Clin Oncol, 23 (2005), pp. 3243-3256

$\underline{24}$

J. Holash, S.J. Wiegand, G.D. Yancopoulos

New model of tumor angiogenesis: dynamic balance between vessel regression and growth mediated by angiopoietins and VEGF

Oncogene, 18 (1999), pp. 5356-5362

$\underline{25}$

D.H. Johnson, L. Fehrenbacher, W.F. Novotny, R.S. Herbst, J.J. Nemunaitis, D.M. Jablons, et al.

Randomized phase II trial comparing bevacizumab plus carboplatin and paclitaxel with carboplatin and paclitaxel alone in previously untreated locally advanced or metastatic non-small-cell lung cancer

J Clin Oncol, 22 (2004), pp. 2184-2191

$\underline{26}$

A. Sandler, R. Gray, M.C. Perry, J. Brahmer, J.H. Schiller, A. Dowlati, et al.

Paclitaxel-carboplatin alone or with bevacizumab for non-small-cell lung cancer

N Engl J Med, 355 (2006), pp. 2542-2550

$\underline{27}$

A. Sandler, J. Yi, S. Dahlberg, M.M. Kolb, L. Wang, J. Hambleton, et al.

Treatment outcomes by tumor histology in Eastern Cooperative Group study E4599 of bevacizumab with paclitaxel/carboplatin for advanced non-small cell lung cancer

J Thorac Oncol, 5 (2010), pp. 1416-1423

$\underline{28}$

P.M. Ellis, N. Blais, D. Soulieres, D.N. Ionescu, M. Kashyap, G. Liu, et al.

A systematic review and canadian consensus recommendations on the use of biomarkers in the treatment of non-small cell lung cancer

J Thorac Oncol, 6 (2011), pp. 1379-1391

$\underline{29}$

M. Reck, J. von Pawel, P. Zatloukal, R. Ramlau, V. Gorbounova, V. Hirsh, et al.

Phase III trial of cisplatin plus gemcitabine with either placebo or bevacizumab as first-line therapy for nonsquamous non-small-cell lung cancer: AVAil

J Clin Oncol, 27 (2009), pp. 1227-1234

$\underline{30}$

Y. Shaked, E. Henke, J.M. Roodhart, P. Mancuso, M.H. Langenberg, M. Colleoni, et al.

Rapid chemotherapy-induced acute endothelial progenitor cell mobilization: implications for antiangiogenic drugs as chemosensitizing agents

Cancer Cell, 14 (2008), pp. 263-273

31

M.A. Socinski, R. Crowell, T.E. Hensing, C.J. Langer, R. Lilenbaum, A.B. Sandler, et al.

Treatment of non-small cell lung cancer, stage IV: ACCP evidence-based clinical practice guidelines (2nd edition)

Chest, 132 (suppl 3) (2007), pp. 277S-289SS

$\underline{32}$

C.G. Azzoli, S. Baker Jr, S. Temin, W. Pao, T. Aliff, J. Brahmer, et al.

American Society of Clinical Oncology Clinical Practice Guideline Update on chemotherapy for stage IV nonsmall-cell lung cancer

J Clin Oncol, 27 (2009), pp. 6251-6266

$\underline{33}$

NCCN Clinical practice guidelines in oncology. Non small cell lung cancer. V.1.2011.Accessed at

http://www.nccn.org/professionals/physician gls/PDF.nscl.pdf.

$\underline{34}$

G.C. Azzoli, S. Baker Jr, S. Temin, W. Pao, T. Aliff, J. Brahmer, et al.

2011 Focused update of 2009 ASCO Clinical Practice Guideline Update on chemotherapy for stage IV nonsmall cell lung cancer

J Clin Oncol, 29 (2011), pp. 3825-3831

$\underline{35}$ 
S. Peters, A.A. Adjei, C. Gridelli, M. Reck, K. Kerr, E. Felip

ESMO Guidelines Working Group. Metastatic non-small-cell lung cancer (NSCLC): ESMO Clinical

Practice Guidelines for diagnosis, treatment and follow-up

Ann Oncol, 23 (Suppl 7) (2012) vii56-64

$\underline{36}$

J.C. Soria, A. Mauguen, M. Reck, A.B. Sandler, N. Saijo, D.H. Johnson, et al.

Systematic review and meta-analysis of randomised, phase II/III trials adding bevacizumab to platinumbased chemotherapy as first-line treatment in patients with advanced non-small-cell lung cancer

Ann Oncol, 24 (2013), pp. 20-30

$\underline{37}$

M.A. Socinski, C.J. Langer, J.E. Huang, M.M. Kolb, P. Compton, L. Wang, et al.

Safety of bevacizumab in patients with non-small-cell lung cancer and brain metastases

J Clin Oncol, 27 (2009), pp. 5255-5261

$\underline{38}$

A.J. Wozniak, J. Garst, M. Jahanzeb, M.P. Kosty, R. Vidaver, S. Beatty, et al.

Clinical outcomes (CO) for special populations of patients (pts) with advanced non-small cell lung cancer (NSCLC): results from ARIES, a bevacizumab (BV) observational cohort study (OCS)

J Clin Oncol, 28 (15 suppl) (2010) abstr 7618

$\underline{39}$

B. Besse, S.F. Lasserre, P. Compton, J. Huang, S. Augustus, U.P. Rohr

Bevacizumab safety in patients with central nervous system metastases

Clin Cancer Res, 16 (2010), pp. 269-278

$\underline{40}$

L. Crinò, E. Dansin, P. Garrido, F. Griesinger, J. Laskin, N. Pavlakis, et al.

Safety and efficacy of first-line bevacizumab-based therapy in advanced non-squamous non-small-cell lung cancer (SAiL, MO19390): a phase 4 study

Lancet Oncol, 11 (2010), pp. 733-740

$\underline{41}$

A.C. Hardy-Bessard, R. Delva, X. Pivot, M. Espié, F. Dalenc, M.A. Coulon Sfairi, et al.

Safety and efficacy of bevacizumab combined with taxanes in the first-linetreatment of metastatic breast cancer: ATHENA study-France

Bull Cancer, 99 (2012), pp. 609-618

$\underline{42}$

V.A. Miller, P. O'Connor, C. Soh, F. Kabbinavar

A randomized, double-blind, placebo-controlled, phase IIIb trial (ATLAS) comparing bevacizumab (B) therapy with or without erlotinib $(E)$ after completion of chemotherapy with $B$ for first line treatment of locally advanced, recurrent, or metastatic non-small cell lung cancer (NSCLC)

J Clin Oncol, 27 (18 suppl) (2009) abstr LBA8002

$\underline{43}$

C.P. Carden, J.M. Larkin, M.A. Rosenthal

What is the risk of intracranial bleeding during anti-VEGF therapy?

Neurooncol, 10 (2008), pp. 624-630

$\underline{44}$

N.B. Leighl, J. Bennouna, J. Yi, N. Moore, J. Hambleton, H. Hurwitz

Bleeding events in bevacizumab-treated cancerpatients who received full-dose anticoagulation and remained on study

Br J Cancer, 104 (2011), pp. 413-418

$\underline{45}$

F. Griesinger, J.J. Laskin, N. Pavlakis

Safety of first-line bevacizumab- based therapy with concomitant cardiovascular or anticoagulation medication in advanced or recurrent nonsquamous non-small cell lung cancer (NSCLC) in MO19390 (SAiL) J Clin Oncol, 26 (suppl) (2008) abstract 8049

$\underline{46}$

A.B. Sandler, J.H. Schiller, R. Gray, I. Dimery, J. Brahmer, M. Samant, et al. 
Retrospective evaluation of the clinical and radiographic risk factors associated with severe pulmonary hemorrhage in first-line advanced, unresectable non-small-cell lung cancer treated with carboplatin and paclitaxel plus bevacizumab

J Clin Oncol, 27 (2009), pp. 1405-1409

$\underline{47}$

M. Reck, F. Barlesi, L. Crinò, C.I. Henschke, D. Isla, S. Stiebeler, et al.

Predicting and managing the risk of pulmonary in patients with NSCLC treated with bevacizumab: a consensus report from a panel of experts

Ann Oncol, 23 (2012), pp. 1111-1120

$\underline{48}$

D.R. Spigel, J.D. Hainsworth, D.A. Yardley, E. Raefsky, J. Patton, N. Peacock, et al.

Tracheoesophageal fistula formation in patients with lung cancer treated with chemoradiation and bevacizumab

J Clin Oncol, 28 (2010), pp. 43-48

$\underline{49}$

M.A. Socinski, T.E. Stinchcombe, J.S. Halle, D.T. Moore, M.T. Tynan, et al.

Incorporation of bevacizumab and erlotinib with induction and concurrent carboplatin /paclitaxel and 74 Gy of thoracic radiotherapy in stage III non-small cell lung cancer

J Clin Oncol (2009), p. 27 abstract 7528

$\underline{50}$

J.D. Patel, T.A. Hensing, A. Rademaker, E.M. Hart, M.G. Blum, D.T. Milton, et al.

Phase II study of pemetrexed and carboplatin plus bevacizumab with maintenance pemetrexed and bevacizumab as first-line therapy for non-squamous non-small-cell lung cancer

J Clin Oncol, 27 (2009), pp. 3284-3289

$\underline{51}$

J.D. Patel, P. Bonomi, M.A. Socinski, R. Govindan, S. Hong, C. Obasaju, et al.

Treatment rationale and study design for the PointBreak study: a randomized, open-label phase III study of pemetrexed/carboplatin/bevacizumab followed by maintenance pemetrexed/bevacizumab versus

paclitaxel/carboplatin/bevacizumab followed by maintenance bevacizumab in patients with stage IIIB or IV non-squamous non-small-cell lung cancer

Clin Lung Cancer, 10 (2009), pp. 252-256

$\underline{52}$

J. Patel, M.A. Socinski, E.B. Garon, C.H. Reynolds, D.R. Spigel, R.C. Hermann, et al.

$A$ randomized, open-label, phase 3 , superiority study of pemetrexed (pem)+carboplatin $(\mathrm{Cb})+$ bevacizumab (B) followed by maintenance Pem $+B$ versus paclitaxel $(\mathrm{Pac})+\mathrm{Cb}+\mathrm{B}$ Followed By maintenance $\mathrm{B}$ in patients with stage IIIB or IV non-squamous non-small cell lung cancer

J Thorac Oncol, 7 (suppl 4) (2012), p. S336

$\underline{53}$

C.J. Langer, M.A. Socinski, J.D. Patel, A. Sandler, J.H. Schiller, L. Leon, et al.

Efficacy and safety of paclitaxel and carboplatin with bevacizumab for the first-line treatment of patients with non-squamous non-small cell lung cancer (NSCLC): analyses based on age in the phase III PointBreak and E4599 trials

J Clin Oncol, 31 (2013) (suppl): abstr 8073

$\underline{54}$

R. Zinner, H.J. Ross, R. Weaver, R. Govindan, V.R. Holden, N.M. Chowhan, et al.

Randomized, open-label, phase III study of pemetrexed plus carboplatin (PemC) followed by maintenance pemetrexed versus paclitaxel/carboplatin/bevacizumab (PCB) followed by maintenance bevacizumab in patients with advanced nonsquamous (NS) non-small cell lung cancer (NSCLC)

J Clin Oncol, 31 (2013) (suppl; abstr LBA8003)

$\underline{55}$

J.L. Spratlin, R.B. Cohen, M. Eadens, L. Gore, D.R. Camidge, S. Diab, et al.

Phase I pharmacologic and biologic study of ramucirumab (IMC-1121B), a fully human immunoglobulin G1 monoclonal antibody targeting the vascular endothelial growth factor receptor-2

J Clin Oncol, 28 (2010), pp. 780-787

$\underline{56}$

D.R. Camidge, M.S. Ballas, S. Dubey, M. Haigentz, P.J. Rosen, J.F. Spicer, et al. 
A phase II, open-label study of ramucirumab (IMC-1121B), an IgG1 fully human monoclonal antibody (MAb) targeting VEGFR-2, in combination with paclitaxel and carboplatin as firstline therapy in patients (pts) with stage IIIb/IV non small cell lung cancer (NSCLC)

J Clin Oncol (2010), p. 28 abstract 7588

$\underline{57}$

G. Scagliotti, S. Novello, J. von Pawel, M. Reck, J.R. Pereira, M. Thomas, et al.

Phase III study of carboplatin and paclitaxel alone or with sorafenib in advanced non small-cell lung cancer J Clin Oncol, 28 (2010), pp. 1835-1842

$\underline{58}$

U. Gatzemeier, T. Eisen, A. Santoro, L. Paz-Ares, J. Bennouna, M. Liao, et al.

Sorafenib (S) + gemcitabine/ cisplatin (GC) vs. GC alone in the first-line treatment of advanced non-small cell lung cancer (NSCLC): Phase III NSCLC research experience utilizing sorafenib (NEXUS) trial

Ann Oncol, 21 (2010), p. viii

$\underline{59}$

G.R. Blumenschein Jr, F. Kabbinavar, H. Menon, T.S. Mok, J. Stephenson, J.T. Beck, et al.

A phase II, multicenter, open-label randomized study of motesanib or bevacizumab in combination with paclitaxel and carboplatin for advanced non-squamous non-small-cell lung cancer

Ann Oncol, 22 (2011), pp. 2057-2067

$\underline{60}$

G. Scagliotti, I. Vynnychenko, Y. Ichinose, K. Park, K. Kubota, F.H. Blackhall, et al.

An international, randomized, placebo-controlled, double-blind phase III study (MONET1) of motesanib plus carboplatin/ paclitaxel (C/P) in patients with advanced non-squamous non-small cell lung cancer (NSCLC) J Clin Oncol, 30 (2012), pp. 172-178

$\underline{61}$

A. Hollebecque, C. Massard, J.C. Soria

Vascular disrupting agents: a delicate balance between efficacy and activity

Curr Opin Oncol, 24 (2012), pp. 305-315

$\underline{62}$

M.J. McKeage, J. Von Pawel, M. Reck, M.B. Jameson, M.A. Rosenthal, R. Sullivan, et al.

Randomised phase II study of ASA404 combined with carboplatin and paclitaxel in previously untreated advanced non small cell lung cancer

Br J Cancer, 99 (2008), pp. 2006-2012

$\underline{63}$

M.J. McKeage, M. Reck, M.B. Jameson, M.A. Rosenthal, D. Gibbs, P.N. Mainwaring, et al.

Phase II study of ASA404 (vadimezan, 5,6-dimethylxanthenone-4-acetic acid/DMXAA) 1,800 mg/m(2)

combined with carboplatin and paclitaxel in previously untreated advanced non-small cell lung cancer Lung Cancer, 65 (2009), pp. 192-197

$\underline{64}$

P.N. Lara Jr, J.Y. Douillard, K. Nakagawa, J. von Pawel, M.J. McKeage, I. Albert, et al.

Randomized phase III placebo-controlled trial of carboplatin and paclitaxel with or without the vascular disrupting agent vadimezan (ASA404) in advanced non-small-cell lung cancer

J Clin Oncol, 29 (2011), pp. 2965-2971

$\underline{65}$

M. Fukua, S. Yano, G. Giaccone, et al.

Multi-institutional randomized phase II trial of gefitinib for previously treated patients with advanced nonsmall-cell lung cancer

J Clin Oncol, 21 (2003), pp. 2237-2246

$\underline{66}$

M.G. Kris, R.B. Natale, R.S. Herbst, T.J. Lynch Jr, D. Prager, C.P. Belani, et al.

Efficacy of gefitinib, an inhibitor of the epidermal growth factor receptor tyrosine kinase, in symptomatic patients with non-small cell lung cancer: a randomized trial

JAMA, 290 (2003), pp. 2149-2158

$\underline{67}$

G. Giaccone, R.S. Herbst, C. Manegold, G. Scagliotti, R. Rosell, V. Miller, et al.

Gefitinib in combination with gemcitabine and cisplatin in advanced non small-cell lung cancer: a phase III trial-INTACT 1 
$\underline{68}$

R.S. Herbst, G. Giaccone, J.H. Schiller, R.B. Natale, V. Miller, C. Manegold, et al.

Gefitinib in combination with paclitaxel and carboplatin in advanced non small-cell lung cancer: a phase III trial-INTACT 2

J Clin Oncol, 22 (2004), pp. 785-794

$\underline{69}$

U. Gatzemeier, A. Pluzanska, A. Szczesna, E. Kaukel, J. Roubec, F. De Rosa, et al.

Phase III study of erlotinib in combination with cisplatin and gemcitabine in advanced non-small-cell lung cancer: The Tarceva lung cancer investigation trial

J Clin Oncol, 25 (2007), pp. 1545-1552

$\underline{70}$

R.S. Herbst, D. Prager, R. Hermann, L. Fehrenbacher, B.E. Johnson, A. Sandler, et al.

TRIBUTE Investigator Group. TRIBUTE: a phase III trial of erlotinib hydrochloride (OSI-774) combined with carboplatin and paclitaxel chemotherapy in advanced non-small-cell lung cancer

J Clin Oncol, 23 (2005), pp. 5892-5899

$\underline{71}$

N. Thatcher, A. Chang, P. Parikh, J. Rodrigues Pereira, T. Ciuleanu, J. von Pawel, et al.

Gefitinib plus best supportive care in previously treated patients with refractory advanced non-small-cell lung cancer: results from a randomised, placebo-controlled, multicentre study (Iressa Survival Evaluation in Lung cancer)

Lancet, 366 (2005), pp. 1527-1537

$\underline{72}$

T.S. Mok, Y.L. Wu, S. Thongprasert, et al.

Gefitinib or carboplatin-paclitaxel in pulmonary adenocarcinoma

N Engl J Med, 361 (2009), pp. 947-957

$\underline{73}$

$\bar{M}$. Fukuoka, Y.L. Wu, S. Thongprasert, P. Sunpawerawong, S.S. Leong, V. Sriuranpong, et al.

Biomarker analyses and final overall survival results from a phase III randomised, open-label, first-line study of gefitinib versus carboplatin/paclitaxel in clinically selected patients with advanced non-small cell lung cancer in Asia (IPASS)

J Clin Oncol, 29 (2011), pp. 2866-2874

$\underline{74}$

S. Thongprasert, E. Duffield, N. Saijo, Y.L. Wu, J.C. Yang, D.T. Chu, et al.

Health-related quality-of-life in a randomized phase III first-line study of gefitinib versus

carboplatin/paclitaxel in clinically selected patients from Asia with advanced NSCLC (IPASS)

J Thorac Oncol, 6 (11) (2011), pp. 1872-1880

$\underline{75}$

T. Mitsudomi, S. Morita, Y. Yatabe, S. Negoro, I. Okamoto, J. Tsurutani, et al.

Gefitinib versus cisplatin plus docetaxel in patients with non-small-cell lung cancer harbouring mutations of the epidermal growth factor receptor (WJTOG3405): an open label, randomised phase 3 trial

Lancet Oncol, 11 (2010), pp. 121-128

$\underline{76}$

J.Y. Han, K. Park, S.W. Kim, D.h. Lee, H.T. Kim, M.J. Ahn, et al.

First-SIGNAL: first-line single agent Iressa versus gemcitabine and cisplatin trial in never-smokers with adenocarcinoma of the lung

J Clin Oncol, 30 (2012), pp. 1122-1128

$\underline{77}$

$\bar{M}$. Maemondo, A. Inoue, K. Kobayashi, S. Sugawara, S. Oizumi, H. Isobe, et al.

Gefitinib or chemotherapy for non-small-cell lung cancer with mutated EGFR

N Engl J Med, 362 (2010), pp. 2380-2388

$\underline{78}$

C. Zhou, Y.L. Wu, G. Chen, J. Feng, X.Q. Liu, C. Wang, et al.

Erlotinib versus chemotherapy as first line treatment for patients with advanced EGFR mutation positive non-small cell lung cancer (OPTIMAL, CTONG-802): a multicentre, open label, randomised phase 3 study Lancet Oncol, 12 (2011), pp. 735-742 
R. Rosell, E. Carcereny, R. Gervais, A. Vergnenegre, B. Massuti, E. Felip, et al.

Erlotinib versus chemotherapy as first line treatment for European patients with advanced EGFR mutation positive non-small cell lung cancer (EURTAC): a multicentre, open label,randomised phase 3 study

Lancet Oncol, 13 (2012), pp. 239-246

$\underline{80}$

S. Heon, B.Y. Yeap, N.I. Lindeman, V.A. Joshi, M. Butaney, G.J. Britt, et al.

The impact of initial gefitinib or erlotinib versus chemotherapy on central nervous system progression in advanced non-small cell lung cancer with EGFR mutations

Clin Cancer Res, 18 (2012), pp. 4406-4414

$\underline{81}$

S. Kobayashi, H. Ji, Y. Yuza, M. Meyerson, K.K. Wong, D.G. Tenen, et al.

An alternative inhibitor overcomes resistance caused by a mutation of the epidermal growth factor receptor

Cancer Res, 65 (2005), pp. 7096-7101

82

G.R. Oxnard, M.E. Arcila, C.S. Sima, G.J. Riely, J. Chmielecki, M.G. Kris, et al.

Acquired resistance to EGFR tyrosine kinase inhibitors in EGFR-mutant lung cancer: distinct natural history of patients with tumors harboring the T790M mutation

Clin Cancer Res, 17 (2011), pp. 1616-1622

$\underline{83}$

V.A. Miller, V. Hirsh, J. Cadranel, Y.M. Chen, K. Park, S.W. Kim, et al.

Afatinib versus placebo for patients with advanced, metastatic non-small-cell lung cancer after failure of erlotinib, gefitinib, or both, and one or two lines of chemotherapy (LUX-Lung 1): a phase $2 b / 3$ randomised trial

Lancet Oncol, 13 (2012), pp. 528-538

$\underline{84}$

J.C. Yang, J.Y. Shih, W.C. Su, T.C. Hsia, C.M. Tsai, S.H. Ou, et al.

Afatinib for patients with lung adenocarcinoma and epidermal growth factor receptor mutations (LUX-Lung 2): a phase 2 trial

Lancet Oncol, 13 (2012), pp. 539-548

$\underline{85}$

J.C. Yang, M.H. Schuler, N. Yamamoto, et al.

LUX-Lung 3: a randomized, open-label, phase III study of afatinib versus pemetrexed and cisplatin as firstline treatment for patients with advanced adenocarcinoma of the lung harboring EGFR-activating mutations J Clin Oncol, 30 (suppl) (2012) abstr LBA7500

$\underline{86}$

Y.L. Wu, C. Zhou, C.-P. Hu, F.J. Feng, S. Lu, Y. Huang, et al.

LUX-Lung 6: a randomized, open-label, phase III study of afatinib (A) versus gemcitabine/cisplatin (GC) as first-line treatment for Asian patients (pts) with EGFR mutation-positive (EGFR $M+$ ) advanced adenocarcinoma of the lung

J Clin Oncol, 31 (suppl) (2013) abstr 8016

$\underline{87}$

Available from: http://clinicaltrials.gov/ct2/show/NCT01466660.

$\underline{88}$

Available from: http://clinicaltrials.gov/ct2/show/NCT01774721.

$\underline{89}$

F. Ciardiello, G. Tortora

A novel approach in the treatment of cancer: targeting the epidermal growth factor receptor

Clin Cancer Res, 7 (2001), pp. 2958-2970

$\underline{90}$

V. Grunwald, M. Hidalgo

Developing inhibitors of the epidermal growth factor receptor for cancer treatment

J Natl Cancer Inst, 95 (2003), pp. 851-867

$\underline{91}$

C.A. Butts, D. Bodkin, E.L. Middleman, C.W. Englund, D. Ellison, Y. Alam, et al. 
Randomized phase II study of gemcitabine plus cisplatin or carboplatin, with or without cetuximab, as firstline therapy for patients with advanced or metastatic non small-cell lung cancer

J Clin Oncol, 25 (2007), pp. 5777-5784

$\underline{92}$

R. Rosell, G. Robinet, A. Szczesna, R. Ramlau, M. Constenla, B.C. Mennecier, et al.

Randomized phase II study of cetuximab plus cisplatin/vinorelbine compared with cisplatin/vinorelbine

alone as first-line therapy in EGFR expressing advanced non-small-cell lung cancer

Ann Oncol, 19 (2008), pp. 362-369

$\underline{93}$

R. Pirker, J.R. Pereira, A. Szczesna, J. von Pawel, M. Krzakowski, R. Ramlau, et al.

FLEX Study Team. Cetuximab plus chemotherapy in patients with advanced non-small-cell lung cancer

(FLEX): an open-label randomized phase III trial

Lancet, 373 (2009), pp. 1525-1531

$\underline{94}$

T.J. Lynch, T. Patel, L. Dreisbach, M. McCleod, W.J. Heim, R.C. Hermann, et al.

Cetuximab and first line taxane/carboplatin chemotherapy in advanced non-small cell lung cancer: results of the randomized multicenter phase III trial BMS099

J Clin Oncol, 28 (2010), pp. 911-917

$\underline{95}$

H. Lin, J. Jiang, X. Liang, X. Zhou, R. Huang

Chemotherapy with cetuximab or chemotherapy alone for untreated advanced non-small-cell lung cancer: a systematic review and meta-analysis

Lung Cancer, 70 (2010), pp. 57-62

$\underline{96}$

E.M. Ibrahim, K.M. Abouelkhair, O.A. Al-Masri, N.C. Chaudry, G.A. Kazkaz

Cetuximab-based therapy is effective in chemotherapy-naïve patients with advanced and metastatic nonsmall-cell lung cancer: a meta-analysis of randomized controlled trials

Lung, 189 (2011), pp. 193-198

$\underline{97}$

P. Chen, L. Wang, B. Liu, H.Z. Zhang, H.C. Liu, Z. Zou

EGFR targeted therapies combined with chemotherapy for treating advanced non-small-cell lung cancer: a meta-analysis

Eur J Clin Pharmacol, 67 (2011), pp. 235-243

$\underline{98}$

H. Kimura, K. Sakai, T. Arao, T. Shimoyama, T. Tamura, K. Nishio

Antibody-dependent cellular cytotoxicity of cetuximab against tumor cells with wild-type or mutant epidermal growth factor receptor

Cancer Sci, 98 (2007), pp. 1275-1280

$\underline{99}$

P. Matar, F. Rojo, R. Cassia

Moreno-Bueno G, Di Cosimo S, Tabernero J, et al. Combined epidermal growth factor receptor targeting with the tyrosine kinase inhibitor gefitinib (ZD1839) and the monoclonal antibody cetuximab (IMC-C225): superiority over single-agent receptor targeting

Clin Cancer Res, 10 (2004), pp. 6487-6501

$\underline{100}$

R. Pirker, J.R. Pereira, J. von Pawel, M. Krzakowski, R. Ramlau, K. Park, et al. EGFR expression as a predictor of survival for first-line chemotherapy plus cetuximab in patients with advanced non-small-cell lung cancer: analysis of data from the phase 3 FLEX study

Lancet Oncol, 13 (2012), pp. 33-42

$\underline{101}$

L. Licitra, S. Störkel, K.M. Kerr, E. Van Cutsem, R. Pirker, F.R. Hirsch, et al.

Predictive value of epidermal growth facrtor receptor expression for first line chemotherapy plus cetuximab in patients with head and neck and colorectal cancer: analysis of data from the EXTREME and CRYSTAL studies

Eur J Cancer, 49 (2013), pp. 1161-1168

$\underline{102}$ 
NCCN Practice Guideline in Non-Small Cell Lung Cancer 2.2013.

Availableat:http://www.nccn.org/professionals/physician gls/f guidelines.asp. Accessed: June 24, 2013.

$\underline{103}$

R. Dienstmann, E. Felip

Necitumumab in the treatment of advanced non-small cell lung cancer: translation from preclinical to clinical development

Expert Opin Biol Ther, 11 (2011), pp. 1223-1231

$\underline{104}$

Available from: http://www.clinicaltrials.gov/show/NCT00982111.

$\underline{105}$

Available from: http://www.clinicaltrials.gov/show/NCT00981058.

$\underline{106}$

J.P. Koivunen, C. Mermel, K. Zejnullahu, C. Murphy, E. Lifshits, A.J. Holmes, et al.

EML4-ALK fusion gene and efficacy of an ALK kinase inhibitor in lung cancer

Clin. Cancer Res, 14 (2008), pp. 4275-4283

$\underline{107}$

D.W. Wong, E.L. Leung, K.K. So, I.Y. Tam, A.D. Sihoe, L.C. Cheng, et al.

The EML4-ALK fusion gene is involved in various histologic types of lung cancers from non smokers with wild-type EGFR and KRAS

Cancer, 115 (2009), pp. 1723-1733

$\underline{108}$

A.T. Shaw, B.Y. Yeap, M. Mino-Kenudson, S.R. Digumarthy, D.B. Costa, R.S. Heist, et al.

Clinical features and outcome of patients with non-small-cell lung cancer who harbour EML4-ALK

J Clin Oncol, 27 (2009), pp. 4247-4253

$\underline{109}$

K. Inamura, K. Takeuchi, Y. Togashi, S. Hatano, H. Ninomiya, N. Motoi, et al.

EML4-ALK lung cancers are characterized by rare other mutations, a TTF-1 cell lineage, an acinar histology, and young onset

Mod Pathol, 22 (2009), pp. 508-515

$\underline{110}$

E.L. Kwak, D.R. Camidge, J. Clark, G.I. Shapiro, R.G. Maki, M.J. Ratain, et al.

Clinical activity observed in a phase 1 dose-escalation trial of an oral c-met and ALK inhibitor, PF-02341066

J Clin Oncol, 27 (15S) (2009) abstract 3509

$\underline{111}$

E.L. Kwak, Y.J. Bang, D.R. Camidge, A.T. Shaw, B. Solomon, R.G. Maki, et al.

Anaplastic lymphoma kinase inhibition in non-small-cell lung cancer

N Engl J Med, 363 (2010), pp. 1693-1703

$\underline{112}$

D.R. Camidge, Y. Bang, E.L. Kwak, A.T. Shaw, A.J. lafrate, R.G. Maki, et al.

Progression-free survival (PFS) from a phase I study of crizotinib (PF-02341066) in patients with ALK-

positive non-small-cell lung cancer (NSCLC)

J Clin Oncol, 29 (suppl) (2011) abstract 2501

$\underline{113}$

L. Crinò, D. Kim, G.J. Riely, P.A. Janne, F.H. Blackhall, D.R. Camidge, et al.

Initial phase II results with crizotinib in advanced ALK-positive non-small cell lung cancer (NSCLC): PROFILE 1005

J Clin Oncol, 29 (suppl) (2011) abstract 7514

$\underline{114}$

A.T. Shaw, D.-W. Kim, K. Nakagawa, T. Seto, L. Crinò, et al.

Crizotinib versus chemotherapy in advanced ALK-positive lung cancer

N Engl J Med, 368 (2013), pp. 2385-2394

$\underline{115}$

A.T. Shaw, A.M. Varghese, B.J. Solomon, D.B. Costa, S. Novello, M. Mino-Kenudson, et al.

Pemetrexed-based chemotherapy in patients with advanced, ALK-positive non-small cell lung cancer

Ann Oncol, 24 (2013), pp. 59-66

$\underline{116}$ 
Available from: http://clinicaltrials.gov/ct2/show/NCT01639001.

$\underline{117}$

Y.J. Bang

Treatment of ALK-positive non-small cell lung cancer

Arch Pathol Lab Med, 136 (2012), pp. 1201-1204

$\underline{118}$

E. Thunnissen, L. Bubendorf, D. Manfred, G. Elmberger, K. Kerr, F. Lopez-Rios, et al.

EML4-ALK testing in non-small cell carcinomas of the lung: a review with recommendations

Virchows Arch, 461 (2012), pp. 245-257

$\underline{119}$

L. Horn, W. Pao

EML4-ALK: homing in on a new target in non-small-cell lung cancer

J Clin Oncol, 27 (2009), pp. 4232-4235

$\underline{120}$

R. Mehra, D.R. Camidge, S. Sharma, E. Felip, T.a.n. DS-W, J.F. Vansteenkiste, et al.

First-in-human phase I study of the ALK inhibitor LDK378 in advanced solid tumors

J Clin Oncol, 30 (suppl) (2012) abstract 3007

$\underline{121}$

A.T. Shaw, R. Mehra, D.-W. Kim, E. Felip, L.Q.M. Chow, D.R. Camidge, et al.

Clinical activity of the ALK inhibitor LDK378 in advanced, ALK-positive NSCLC

J Clin Oncol, 31 (suppl) (2013) abstract 8010

$\underline{122}$

Available from: http://clinicaltrials.gov/ct2/show/ NCT01828112.

$\underline{123}$

Available from: http://clinicaltrials.gov/ct2/show/NCT01828099.

$\underline{124}$

K. Nakagawa, K. Kiura, M. Nishio, T. Seto, M. Maemondo, A. Inoue, et al.

A phase I/II study with a highly selective ALK inhibitor CH5424802 in ALK-positive non-small cell lung cancer (NSCLC) patients: updated safety and efficacy results from AF-001JP

J Clin Oncol, 31 (suppl) (2013) abstr 8033

$\underline{125}$

D.R. Camidge, L. Bazhenova, R. Salgia, G.J. Weiss, C.J. Langer, A.T. Shaw, et al.

First-in-human dose-finding of the ALK/EGFR inhibitor AP26113 in patients with advanced malignancies:

Updated results

J Clin Oncol, 31 (suppl) (2013) abstr 8031

$\underline{126}$

J.S. Temel, J.A. Greer, A. Muzikansky, E.R. Gallagher, S. Admane, V.A. Jackson, et al.

Early palliative care for patients with metastatic non-small-cell lung cancer

N Engl J Med, 363 (2010), pp. 733-742

$\underline{127}$

X. Bonfill, C. Serra, M. Sacristán, M. Nogué, F. Losa, J. Montesinos

Second-line chemotherapy for non-small-cell lung cancer

Cochrane Database Syst Rev, 4 (2001), p. CD002804

$\underline{128}$

E. Massarelli, F. Andre, D.D. Liu, J.J. Lee, M. Wolf, A. Fandi, et al.

A retrospective analysis of the outcome of patients who have received two prior chemotherapy regimens including platinum and docetaxel for recurrent non-small cell lung cancer

Lung Cancer, 39 (2003), pp. 55-61

$\underline{129}$

H. Hayashi, I. Okamoto, S. Morita, M. Taguri, K. Nakagawa

Post-progression survival for first-line chemotherapy of patients with advanced non-small-cell lung cancer Ann Oncol, 23 (2012), pp. 1537-1541

$\underline{130}$

M. Di Maio, P. Chiodini, V. Georgoulias, D. Hatzidaki, K. Takeda, F.M. Wachters, et al.

Meta-analysis of single-agent chemotherapy compared with combination chemotherapy as second-line treatment of advanced non-small-cell lung cancer 
$\underline{131}$

F.V. Fossella, R. DeVore, R.N. Kerr, J. Crawford, R.R. Natale, F. Dunphy, et al.

Randomized phase III trial of docetaxel versus vinorelbine or ifosfamide in patients with advanced nonsmall-cell lung cancer previously treated with platinum-containing chemotherapy regimens. The TAX 320 Non-Small Cell Lung Cancer Study Group

J Clin Oncol, 18 (2000), pp. 2354-2362

$\underline{132}$

F.A. Shepherd, J. Dancey, R. Ramlau, K. Mattson, R. Gralla, M. O'Rourke, et al.

Prospective randomized trial of docetaxel versus best supportive care in patients with non-small-cell lung cancer previously treated with platinum-based chemotherapy

J Clin Oncol, 18 (2000), pp. 2095-2103

Loading

\section{3}

M. Di Maio, F. Perrone, P. Chiodini, C. Gallo, C. Camps, W. Schuette, et al.

Individual patient data meta-analysis of docetaxel administered once every 3 weeks compared with once every week second-line treatment of advanced non-small-cell lung cancer

J Clin Oncol, 25 (2007), pp. 1377-1382

$\underline{134}$

N. Hanna, F.A. Shepherd, F.V. Fossella, J.R. Pereira, F. De Marinis, J. von Pawel, et al.

Randomized phase III trial of pemetrexed versus docetaxel in patients with non-small-cell lung cancer previously treated with chemotherapy

J Clin Oncol, 22 (2004), pp. 1589-1597

$\underline{135}$

P. Peterson, K. Park, F. Fossella, U. Gatzemeier, W. John, G. Scagliotti

Is pemetrexed more effective in adenocarcinoma and large cell lung cancer than in squamous cell carcinoma? A retrospective analysis of a phase III trial of pemetrexed vs docetaxel in previously treated patients with advanced non-small cell lung cancer

J Thorac Oncol, 2 (2007), p. $S 851$ [abstract]

$\underline{136}$

G. Scagliotti, T. Brodowicz, F.A. Shepherd, C. Zielinski, J. Vansteenkiste, C. Manegold, et al.

Treatment by-histology interaction analyses in three phase III trials show superiority of pemetrexed in nonsquamous non-small cell lung cancer

J Thorac Oncol, 6 (2011), pp. 64-70

$\underline{137}$

M.P. Fanucchi, F.V. Fossella, R. Belt, R. Natale, P. Fidias, D.P. Carbone, et al.

Randomized phase II study of bortezomib alone and bortezomib in combination with docetaxel in previously treated advanced non-small-cell lung cancer

J Clin Oncol, 24 (2006), pp. 5025-5033

$\underline{138}$

V. Georgoulias, A. Agelidou, K. Syrigos, A. Rapti, M. Agelidou, J. Nikolakopoulos, et al.

Second-line treatment with irinotecan plus cisplatin vs cisplatin of patients with advanced non-small-cell lung cancer pretreated with taxanes and gemcitabine: a multicenter randomised phase II study

Br J Cancer, 93 (2005), pp. 763-769

$\underline{139}$

V. Georgoulias, C. Kouroussis, A. Agelidou, I. Boukovinas, P. Palamidas, E. Stavrinidis, et al. Irinotecan plus gemcitabine vs irinotecan for the second-line treatment of patients with advanced nonsmall-cell lung cancer pretreated with docetaxel and cisplatin: a multicentre, randomised, phase II study Br J Cancer, 91 (2004), pp. 482-488

$\underline{140}$

R. Lilenbaum, M.A. Socinski, N.K. Altorki, L.L. Hart, R.S. Keresztes, S. Hariharan, et al.

Randomized phase II trial of docetaxel/irinotecan and gemcitabine/irinotecan with or without Celecoxib in the second-line treatment of non-small-cell lung cancer

J Clin Oncol, 24 (2006), pp. 4825-4832 
D. Pectasides, M. Pectasides, D. Farmakis, V. Kostopoulou, M. Nikolaou, Gaglia, et al.

Comparison of docetaxel and docetaxel-irinotecan combination as second-line chemotherapy in advanced non-small-cell lung cancer: a randomized phase II trial

Ann Oncol, 16 (2005), pp. 294-299

$\underline{142}$

F.M. Wachters, H.J. Groen, B. Biesma, F.M. Schramel, P.E. Postmus, J.A. Stigt, et al.

A randomised phase II trial of docetaxel versus docetaxel and irinotecan in patients with stage IIIb-IV nonsmall-cell lung cancer who failed first-line treatment

Br J Cancer, 92 (2005), pp. 15-20

$\underline{143}$

F.A. Shepherd, J. Rodrigues Pereira, T. Ciuleanu, E.H. Tan, V. Hirsh, et al.

National Cancer Institute of Canada Clinical Trials Group . Erlotinib in previously treated non-small-cell lung cancer

N Engl J Med, 353 (2005), pp. 123-132

$\underline{144}$

S.T. Kim, J.E. Uhm, J. Lee

Randomized phase II study of gefitinib versus erlotinib in patients with advanced non-small cell lung cancer who failed previous chemotherapy

Lung Cancer, 75 (2012), pp. 82-88

$\underline{145}$

M.A. Socinski, J. Goldman, I. El-Hariry, M. Koczywas, V. Vukovic, L. Horn, et al.

A multicenter phase II study of Genetespib monotherapy in patients with geno4.typically defined advanced non-samll cell lung cancer

Clin. Cancer Res, 19 (2013), pp. 3068-3077

$\underline{146}$

S.S. Ramalingam, G.D. Goss, Z.G. Andric, I. Bondarenko, B. Zaric, T. Ceric, et al.

A randomized study of ganetespib, a heat shock protein 90 inhibitor, in combination with docetaxel versus docetaxel alone for second line adenocarcinoma (Galaxy-1)

J Clin Oncol, 31 (suppl) (2013) abstract LBA 8007

$\underline{147}$

W.X. Qi, Q. Wang, Y.L. Jiang, Y.J. Sun, L.N. Tang, A.N. He, et al.

Overall survival benefits for combining targeted therapy as second-line treatment for advanced non- smallcell-lung cancer: a meta-analysis of published data

PLOS One, 8 (2013), p. e55637

$\underline{148}$

Y.Y. Shao, W.Y. Shau, Z.Z. Lin

Comparison of gefitinib and erlotinib efficacy as third-line therapy for advanced non-small-cell lung cancer Eur J Cancer, 49 (2013), pp. 106-114

$\underline{149}$

K.N. Syrigos, M.W. Saif, E.M. Karapanagiotou, G. Oikonomopoulos, F. De Marinis

The need for third-line treatment in non-small cell lung cancer: an overview of new options

Anticancer Res, 31 (2011), pp. 649-659

$\underline{150}$

R.B. Natale, S. Thongprasert, F.A. Greco, M. Thomas, C.M. Tsai, P. Sunpaweravong, et al. Phase III trial of vandetanib compared with erlotinib in patients with previously treated advanced non small- cell lung cancer

J Clin Oncol, 29 (2011), pp. 1059-1066

$\underline{151}$

J. Lee, V. Hirsh, K. Park, S. Qin, C.R. Blajman, R.P. Perng, et al.

Vandetanib versus placebo in patients with advanced non-small cell lung cancer after prior therapy with an EGFR tyrosine kinase inhibitor (TKI): a randomized, double-blind, phase III trial (ZEPHYR)

J Clin Oncol, 30 (2012), pp. 1114-1121

$\underline{152}$

H.A. Wakelee, J.W. Lee, N.H. Hanna, A.M. Traynor, D.P. Carbone, J.H. Schiller

A double-blind randomized discontinuation phase II study of Sorafenib (BAY 43-9006) in previously treated non-small cell lung cancer patients: Eastern Cooperative Oncology Group study E2501) 
J Thorac Oncol, 7 (2012), pp. 1574-1582

$\underline{153}$

L. Paz-Ares, V. Hirsh, L. Zhang, F. De Marinis, J.C.-H Yang, H. Wakelee, et al.

Monotherapy administration of sorafenib in patients with non-small cell lung cancer: phase III, randomized, double blind, placebo controlled MISSION study

Ann Oncol, 23 (suppl 9) (2012) LBA 33 PR

$\underline{154}$

S. Tian, H. Quan, C. Xie, H. Guo, F. Lü, Y. Xu, J. Li, L. Lou

YN968D1 is a novel and selective inhibitor of vascular endothelial growth factor receptor-2 tyrosine kinase with potent activity in vitro and in vivo

Cancer Sci, 102 (2011), pp. 1374-1380

$\underline{155}$

Y.J. Mi, Y.J. Liang, H.B. Huang, H.Y. Zhao, C.P. Wu, F. Wang, et al.

Apatinib (YN968D1) reverses multidrug resistance by inhibiting the efflux function of multiple ATP-binding cassette transporters

Cancer Res, 70 (2010), pp. 7981-7991

$\underline{156}$

L. Zhang, S.H.I. Meiqi, C. Huang, X. Liu, J.P. Xiong, G. Chen, et al.

A phase II, multicenter, placebo controlled trial of apatinib in patients with advanced non-squamous nonsmall cell lung cancer after two previous treatment regimens

J Clin Oncol, 30 (suppl) (2012) abstract 7548

$\underline{157}$

M. Reck, A. Hermes, E.H. Tan, E. Felip, B. Klughammer, J. Baselga

Tissue sampling in lung cancer: a review in light of the MERIT experience

Lung Cancer, 74 (2011), pp. 1-6

$\underline{158}$

J.R. Brahmer

Harnessing the immune system for the treatment of non-small-cell lung cancer

J Clin Oncol, 31 (2013), pp. 1021-1028

$\underline{159}$

S.L. Topalian, F.S. Hodi, J.R. Brahmer, S.N. Gettinger, D.C. Smith, D.F. McDermot, et al.

Safety, activity, and immune correlates of anti-PD-1 antibody in cancer

N Engl J Med, 366 (2012), pp. 2443-2454

$\underline{160}$

J.R. Brahmer, L. Horn, S.J. Antonia, D.R. Spigel, L. Gandhi, L.V. Sequist, et al.

Survival and long term follow up of the phase I trial of nivolumab (anti-PD-1, BMS-936558; ONO-4538) in patients with previously treated advanced non-small cell lung -cancer

J Clin Oncol, 31 (suppl) (2013) abstract 8030

$\underline{161}$

D.R. Spigel, S.N. Gettinger, L. Horn, R.S. Herbst, L. Gandhi, et al.

Clinical activity, safety, and biomarkers of MPDL3280A, an engineered PD-L1 antibody in patients with locally advanced or metastatic non-small cell lung cancer (NSCLC)

J Clin Oncol, 31 (suppl) (2013) abstr 8008

$\underline{162}$

N.A. Rizvi, S.J. Antonia, L.Q.M. Chow, J.R. Brahmer, R.A. Juergens, H. Borghaei, et al.

A phase I study of nivolumab (anti-PD-1; BMS-936558, ONO-4538) plus platinum-based doublet

chemotherapy in chemotherapy-naive non-small cell lung cancer (NSCLC) patients

J Clin Oncol, 31 (suppl) (2013) abstr 8072

$\underline{163}$

The Elderly Lung Cancer Vinorelbine Italian Study Group

Effects of vinorelbine on quality of life and survival of elderly patients with advanced non-small-cell lung cancer

J Natl Cancer Inst, 91 (1999), pp. 66-72

$\underline{164}$

C. Gridelli, F. Perrone, C. Gallo, S. Cigolari, A. Rossi, F. Piantedosi, et al. 
Chemotherapy for elderly patients with advanced non-small-cell lung cancer: the Multicenter Italian Lung Cancer in the Elderly Study (MILES) phase III randomized trial

J Natl Cancer Inst, 95 (2003), pp. 362-372

$\underline{165}$

C.J. Langer, J. Manola, P. Bernardo, J.W. Kugler, P. Bonomi, D. Cella, et al.

Cisplatin-based therapy for elderly patients with advanced non-small-cell lung cancer: implications of

Eastern Cooperative Oncology Group 5592, a randomized trial

J Natl Cancer Inst, 94 (2002), pp. 173-181

$\underline{166}$

A.G. Pallis, A. Polyzos, I. Boukovinas, A. Agelidou, L. Lamvakas, X. Tsiafaki, et al.

Pooled analysis of elderly patients with non-small cell lung cancer treated with front line

docetaxel/gemcitabine regimen: the Hellenic Oncology Research Group experience

J Thorac Oncol, 3 (2008), pp. 505-510

$\underline{167}$

Tsukada H, Yokoyama A, Nishiwaki Y, Shinkai T, Harada M, Ando M, et al. Lung Cancer Study Group of the Japan Clinical Oncology Group (JCOG). Randomized controlled trial comparing docetaxel(D)-cisplatin (P) combination with $D$ alone in elderly patients (pts) with advanced non-small cell lung cancer

(NSCLC):JCOG0207. ASCO Annual Meeting Proceedings Part I. 2007;25 (18S):7629

$\underline{168}$

T. Abe, A. Yokoyama, K. Takeda, Y. Ohe, S. Kudoh, Y. Ichinose, et al.

Randomized phase III trial comparing weekly docetaxel (D)-cisplatin (P) combination with triweekly $D$ alone in elderly patients (pts) with advanced non-small cell lung cancer (NSCLC): an intergroup trial of

JCOG0803/WJOG4307L

J Clin Oncol, 29 (suppl) (2011) abstr 7509

$\underline{169}$

E. Quoix, G. Zalcman, J.P. Oster, V. Westeel, E. Pichon, A. Lavolé, et al.

Intergroupe Francophone de Cancérologie Thoracique. Carboplatin and weekly paclitaxel doublet

chemotherapy compared with monotherapy in elderly patients with advanced non-small-cell lung cancer:

IFCT-0501 randomised, phase 3 trial

Lancet, 378 (2011), pp. 1079-1088

$\underline{170}$

M.A. Socinski, C.J. Langer, I. Okamoto, J.K. Hon, V. Hirsh, S.R. Dakhil, et al.

Safety and efficacy of weekly nab ${ }^{\circledR}$-paclitaxel in combination with carboplatin as first-line therapy in elderly patients with advanced non-small-cell lung cancer

Ann Oncol, 24 (2013), pp. 314-321

$\underline{171}$

A.G. Pallis, C. Gridelli, J.P. van Meerbeeck, L. Greillier, U. Wedding, D. Lacombe, et al.

EORTC Elderly Task Force and Lung Cancer Group and International Society for Geriatric Oncology (SIOG)

experts' opinion for the treatment of non-small-cell lung cancer in an elderly population

Ann Oncol, 21 (2010), pp. 692-706

$\underline{172}$

M. Jiroutek, D. Johnson, R. Blum, et al.

Prognostic factors in advanced non small cell lung cancer: analysis of Eastern Cooperative Oncology Group trials from 1981-1992

Proc Am Soc Clin Oncol, 17 (1998), p. 461 (abstract 1774)

$\underline{173}$

C. Gridelli, A. Ardizzoni, T. Le Chevalier, C. Manegold, F. Perrone, N. Thatcher, et al.

Treatment of advanced non-small-cell lung cancer patients with ECOG performance status 2: results of an

European Experts Panel

Ann Oncol, 15 (2004), pp. 419-426

$\underline{174}$

C.J. Sweeney, J. Zhu, A.B. Sandler, J. Schiller, C.P. Belani, C. Langer, et al.

Outcome of patients with a performance status of 2 in Eastern Cooperative Oncology Group Study E1594: a

Phase II trial in patients with metastatic nonsmall cell lung carcinoma

Cancer, 92 (2001), pp. 2639-2647 
T.E. Stinchcombe, J. Choi, M.J. Schell, A. Mears, P.E. Jones, R.V. Nachtsheim, et al.

Carboplatin-based chemotherapy in patients with advanced non-small cell lung cancer and a poor

performance status

Lung Cancer, 51 (2006), pp. 237-243

$\underline{176}$

R. Lilenbaum, V.M. Villaflor, C. Langer, K. O'Byrne, M. O'Brien, H.J. Ross, et al.

Single-agent versus combination chemotherapy in patients with advanced non-small cell lung cancer and a performance status of 2: prognostic factors and treatment selection based on two large randomized clinical trials

J Thorac Oncol, 4 (2009), pp. 869-874

$\underline{177}$

C. Reynolds, C. Obasaju, M.J. Schell, X. Li, Z. Zheng, D. Boulware, et al.

Randomized phase III trial of gemcitabine-based chemotherapy with in situ RRM1 and ERCC1 protein levels for response prediction in non small- cell lung cancer

J Clin Oncol, 27 (2009), pp. 5808-5815

$\underline{178}$

Zukin M, Barrios CH, Pereira JR, De Albuquerque Ribeiro R, de Mendonça Beato CA, do Nascimento YN, et al. Randomized phase III trial of single-agent pemetrexed versus carboplatin and pemetrexed in patients with advanced non- small cell lung cancer (NSCLC) and Eastern Cooperative Oncology group performance status of 2. J Clin Oncol. 2013; 17 ahead of print.

$\underline{179}$

R. Lilenbaum, R. Axelrod, S. Thomas, A. Dowlati, L. Seigel, D. Albert, et al.

Randomized phase II trial of erlotinib or standard chemotherapy in patients with advanced non-small-cell lung cancer and a performance status of 2

J Clin Oncol, 26 (2008), pp. 863-869

$\underline{180}$

G. Goss, D. Ferry, R. Wierzbicki, S.A. Laurie, J. Thompson, B. Biesma, et al.

Randomized phase II study of gefitinib compared with placebo in chemotherapy-naive patients with advanced non-small-cell lung cancer and poor performance status

J Clin Oncol, 27 (2009), pp. 2253-2260 